\title{
Static and Dynamic Material Properties of CFRP/epoxy Laminates
}

\author{
Xihong Zhang ${ }^{1, *}$, Hong $\mathrm{Hao}^{1}$, Yanchao $\mathrm{Shi}^{2}$, Jian Cui ${ }^{2}$, Xuejie Zhang ${ }^{2}$
}

1. Tianjin University and Curtin University Joint Research Center of Structural Monitoring and Protection, School of Civil and Mechanical Engineering, Curtin

University, Kent St., Bentley WA 6102, Australia

2. Tianjin University and Curtin University Joint Research Center of Structural

Monitoring and Protection, Tianjin University, China

email: xihong.zhang@curtin.edu.au

Phone: +61 892669108

Abstract

Carbon fiber reinforced polymer (CFRP) has been extensively used to strengthen structures owing to its outstanding mechanical properties. With an increasing threat from terrorist bombing attacks and accidental explosions, the application of CFRP has been extended to mitigate the effect of blast loading on structures. A better understanding of the dynamic material properties of CFRP/epoxy laminates at high strain rates is therefore needed for more reliable analysis and design of CFRP strengthened structures under dynamic loadings. In this study, the unidirectional tensile properties of CFRP (SikaWrap ${ }^{\circledR}-230 \mathrm{C}$ ) and epoxy resin (Sikadur ${ }^{\circledR}$-330) laminates is investigated experimentally over a wide range of strain rates. Quasi-static and low-speed tensile tests are conducted at strain rates varying from $7 \times 10^{-5} \mathrm{~s}^{-1}$ to $0.07 \mathrm{~s}^{-1}$. Then, high-speed tensile tests are performed using a high-speed servo-hydraulic testing machine at strain rate from about $10 \mathrm{~s}^{-1}$ to $240 \mathrm{~s}^{-1}$. The testing results show that both the tensile strength and the stiffness of the CFRP/epoxy laminates are insensitive to loading speed when the strain rate is less than $50 \mathrm{~s}^{-1}$. However, when strain rate is over $50 \mathrm{~s}^{-1}$, both the tensile strength and the coupon stiffness increase with the increase of strain rate. Highspeed camera images are used to assist inspecting the failure modes of CFRP/epoxy laminates. It is found that under high-strain rate tension CFRP/epoxy laminates fail differently from that at low-strain rate. The different failure mode is believed to contribute to the increment of laminate strength. The testing data are analyzed together with available testing results on CFRP/epoxy laminates at various strain rates. Empirical formulas of dynamic increase factor for CFRP material are derived for better prediction of material strength at various strain rates.

Keywords: Carbon fiber reinforced polymer (CFRP); strain rate effect; tensile properties; high-speed testing; DIF 


\section{Introduction}

CFRP, short for carbon fiber reinforced polymer, is a high strength and light weight material which has become notable in construction ever since its successful employments in aerospace, automotive, and marine areas. Owing to its outstanding performance in conventional building construction, the application of CFRP has been extended to structure retrofit against blast and impact loadings. The high strength and lightweight features enables CFRP to significantly increase the flexural resistance capacities of slabs and beams, enhance the axial load bearing capability of columns (as a result of lateral confinement), as well as reduce ejecting fragments of structures subjected to blast and impact loads since it is generally applied as an external layer.

In application, CFRP is normally impregnated in epoxy resin matrix to form CFRP/epoxy laminate. The CFRP/epoxy laminate is a composite material, which consists of a resin matrix and a reinforcement- carbon fiber. The latter governs the composite strength and rigidity. Considerable amount of studies have been carried out to investigate the mechanical properties of various types of CFRP materials. Jacob et al. [1] reviewed and summarized previous testing on FRP composites including not only carbon but also glass, graphite and Kevlar etc. Different techniques including drop weight tube, servo-hydraulic machine, pendulum impact system, Split-Hopkinson Pressure bar (SHPB) etc. are utilized to investigate the behavior of FPR material at different strain rates [2]. Unlike isotropic materials such as steel, the mechanical properties of CFRP depend on its direction. Both the layout and the proportion of fibers significantly influence CFRP/epoxy laminate properties. Hou and Ruiz [3] performed tensile test, compressive test and in-plane shear tests on woven CFRP/epoxy laminates with fiber directions in $0^{\circ}, 45^{\circ}$ and $90^{\circ}$ against the loading direction. It was found that specimens show linear elastic properties in both $0^{\circ}$ and $90^{\circ}$ directions, while tensile test on $45^{\circ}$ specimens give non-linear stress-strain curves. Through reviewing available experimental data, Wisnom [4] observed a tendency of laminate strength to decrease with higher volume of fibers. In addition, size effects were found among different sized specimens primarily in flexural tests [4]. This can probably be attributed to the existence of more defects such as fiber waviness in larger specimens.

Despite a large amount of tests undertaken to examine the dynamic material properties of CFRP material of various types, contradicted testing results are reported. As a result there is no consensus on the significance or even existence of strain rate effect on FRP materials, and the degree of its sensitivity. For instance, Welsh and Harding [5] carried out quasi-static 
1 and dynamic tensile tests on T300 carbon/epoxy laminates at strain rate from $1.5 \times 10^{-4} \mathrm{~s}^{-1}$ to

$2700 \mathrm{~s}^{-1}$. The testing results showed an increase in both the tensile strength and elastic

3 modulus of the coupon. Dynamic tensile tests on type T300 carbon/epoxy composite were

4 also conducted by Zhao et al. [6] and Chen et al. [7] respectively using SHPB technique. Both testing results indicated that the tensile strength and the initial modulus increase with the strain rate. Similarly, Gilat et al. [8] utilized SHPB technique on IM7/977 carbon/epoxy composite. The results showed significant strain rate effect on material response. Recently, Al-Zubaidy et al. [9] tested CF130 carbon/epoxy laminates in the strain rate range of $0.000242 \mathrm{~s}^{-1}$ to $87.4 \mathrm{~s}^{-1}$. The increased strain rate was found to lead to increase in material tensile strength and modulus. On the other hand, some opposite conclusions on the effect of strain rate were given based on dynamic testing results on CFRP/epoxy laminates. For example, with dynamic tests on T300 carbon/epoxy laminates, Hou and Ruiz [3] observed insignificant strain rate effect in material tensile strength and modulus, while the shear properties were found to be strain rate dependent. Similar conclusions were made by Taniguchi et al. [10] through their dynamic testing on type T700 carbon/epoxy laminates.

In this paper, unidirectional tensile tests on SikaWrap ${ }^{\circledR}-230$ c with Sikadur ${ }^{\circledR}-330$ carbon/epoxy laminates are carried out at both quasi-static and dynamic states. The dynamic material properties of the CFRP material and the laminates are investigated experimentally. The strain rate effects on the tensile strength, failure strain, and elastic modulus are studied. Dynamic increase factors (DIF) are derived based on the testing results.

\section{Methodology and Theory}

\section{$2.1 \quad$ Testing systems}

Commonly used techniques to investigate material tensile properties include conventional screw driven load frame, servo-hydraulic machine, pendulum impactor, drop weight impact system, high-speed servo-hydraulic machine, and Split-Hopkinson Pressure Bar system. Conventional systems like screw driven frame and servo-hydraulic machine normally can achieve a testing strain rate from quasi-static state to $1 \mathrm{~s}^{-1}$ in the specimen. Split-Hopkinson Pressure Bar (SHPB) is commonly used to determine material strength at strain rates over $100 s^{-1}[6,7]$. The pendulum impactor, drop weight impactor and the high-speed servohydraulic machine are widely used to determine material strength at strain rate above $1 \mathrm{~s}^{-1}$. Dog-bone shaped specimens or straight coupons are most commonly adopted for the dynamic tensile tests. Due to inherit difficulties, the strain rates that can be achieved by a 
1 drop weight impact machine or the pendulum impactor is normally limited to below $100 \mathrm{~s}^{-1}$.

2 Moreover, during a test the velocity of the actuator varies due to interaction with the response of the specimen. It is therefore difficult for the drop weigh impactor or the pendulum impactor to maintain a constant velocity. In this study, servo-hydraulic and highspeed servo-hydraulic machines are used to perform the quasi-static and dynamic tensile tests. The testing setups and machine information are described in detail in section three.

\subsection{Testing requirements for dynamic tensile tests}

Ensuring a state of stress equilibrium through the tested specimen is essential for the validity of testing data in dynamic tests. For quasi-static and low-speed tests, comparing with the loading duration there is more than sufficient time for an elastic wave to travel back and forth many times inside the specimen. The specimens are therefore under quasi-static equilibrium, and generally further validation of stress equilibrium is not necessary. However, for high-speed tests to achieve the state of stress equilibrium is much more difficult since the loading time can be very short. In a dynamic test, a state of dynamic equilibrium is usually pursued, where a minimum number of elastic waves are required to propagate through the specimen $[11,12]$. To estimate the time for one stress wave to travel a round trip in the specimen the following equation can be used

$$
\mathrm{t}=\frac{2 \mathrm{~L}}{\mathrm{c}}
$$

where $L$ is the gauge length of the specimen between the clamping grips; and $c$ is the onedimensional longitudinal elastic stress wave velocity in the testing material, which can be estimated by the relation in Eq. (2)

$$
c=\sqrt{\frac{E}{\rho}}
$$

where $\rho$ is the density of the material, and $\mathrm{E}$ is the Young's modulus.

To achieve dynamic equilibrium, in a SHPB test it normally requires at least three reverberations of the loading wave in the specimen $[13,14]$. Based on dynamic tensile tests using a high-speed servo-hydraulic machine, Xiao verified that the criterion for a valid SHPB test is also applicable to dynamic direct tensile test [15]. It should be noted that there is no quantitative criterion in the literature yet to define the exact number of stress wave reverberation in the specimen to achieve dynamic equilibrium for a uniaxial tensile test. More theoretical and analytical studies therefore need be conducted to define a proper 
testing criterion. In the present study the conclusion drawn in [15] is adopted to determine the validation of testing data.

\section{Experiment Setup}

\subsection{Specimen}

The carbon fiber SikaWrap ${ }^{\circledR}-230 \mathrm{C}$ (manufactured by Sika Australia Pty Limited) is a woven unidirectional carbon fiber fabric designed for structural strengthening applications. It is a mid-range strength CFRP material in its family with a dry fiber tensile strength of $4300 \mathrm{MPa}$ as provided by the manufacturer product sheet. The fiber density is $1.8 \mathrm{~g} / \mathrm{cm}^{3}$ and the fabric sheet has a nominal thickness of $0.131 \mathrm{~mm}$. The epoxy resin used is Sikadur ${ }^{\circledR}-330$ as recommended by the manufacturer. Sikadur ${ }^{\circledR}-330$ is a two-part epoxy impregnation resin. Its tensile strength and elastic modulus are 30MPa and 4.5GPa, respectively.

The preparation of the CFRP/epoxy laminates used the wet lay-up process following the Sika guideline. As shown in Figure 1a, the epoxy is mixed by weight ratio 1:4 of the two substances. A recommended mass of $0.7 \mathrm{~kg} / \mathrm{m}^{2}$ was used to calculate the total amount of epoxy required. Two thirds of the epoxy was spread evenly over a flat base board covered with polyvinyl plastic. Then, the CFRP sheet was carefully laid over the epoxy and gently rolled with a plastic roller in the direction of fiber (Figure 1b). This process ensures the carbon fiber fully impregnated with the resin. The remaining epoxy was then spread over the fiber sheet evenly with the roller (Figure 1c) before another flat board covered with plastic was placed on top of the CFRP sheet. The CFRP/epoxy laminates were cured at room temperature for 72 hours.

The configurations of the specimens to be tested were prepared according to ASTM D3039 [16]. The CFRP/epoxy laminate sheets were sliced into $25 \mathrm{~mm}$ wide strips (Figure 1d). It is imperative that the fibers run parallel to the direction of loading. The CFRP strips were then cut into $25 \mathrm{~mm}$ wide and $450 \mathrm{~mm}$ long coupons for quasi-static and dynamic tests. Mild steel tabs were bonded to both sides of the CFRP coupons. Detailed dimensions for the specimens are shown in Figure 2. For quasi-static test, the central testing gauge length is approximately $128 \mathrm{~mm}$. To achieve high strain rates, the gauge length of the specimen for the dynamic tests were reduced to $50 \mathrm{~mm}$. As shown in Figure $2 \mathrm{~b}$, the tab on one side is left purposely longer than the other end, which is to be grabbed by the fast jaw of the Instron machine used for dynamic testing. The width and the thickness of the gauges were 
measured at their centers and quarter spans after each CFRP coupons were made. An

2 averaged width and laminate thickness are listed in Table 1 and Table 2.

\section{$3 \quad 3.2 \quad$ Testing apparatus}

\subsubsection{Quasi-static and low-speed test}

5 The quasi-static and low-speed test was performed on an Instron UTS-5982 hydraulic machine (Figure 3). The machine has a load capacity of $100 \mathrm{kN}$ with a maximum stroke of $1430 \mathrm{~mm}$ at a controlled constant speed from $5 \times 10^{-5} \mathrm{~mm} / \mathrm{min}$ to $1016 \mathrm{~mm} / \mathrm{min}$. An inbuilt load cell and extensometer were used to measure the force and track the displacement of the specimen. A strain gauge (Type PFL-30-11-1L by $T \mathrm{TML}^{\circledR}$ ) is attached to the middle to the specimen to monitor the strain of the material. The room temperature during the test was around $25^{\circ} \mathrm{C} \pm 5^{\circ} \mathrm{C}$. In the current study, the actuator extension speed was controlled in the range from $1 \mathrm{~mm} / \mathrm{min}$ to $1000 \mathrm{~mm} / \mathrm{min}$, which corresponded to an estimated strain rate of $1.3 \times 10^{-4} \mathrm{~s}^{-1}$ to $0.131 \mathrm{~s}^{-1}$ (actuator speed/specimen gauge length). The true measured strain rates by strain gauges varied from about $7 \times 10^{-5} \mathrm{~s}^{-1}$ to $0.078 \mathrm{~s}^{-1}$. Detailed information of specimen configurations and test parameters are listed in Table 1.

\subsubsection{High-speed test}

The high-speed tensile test was carried out on an Instron VHS 160-20 testing system. The machine utilizes servo-hydraulic and control technology and is capable of providing a controlled testing velocity of up to $25 \mathrm{~m} / \mathrm{s}$ under open loop control and $1 \mathrm{~mm} / \mathrm{s}$ to $1 \mathrm{~m} / \mathrm{s}$ under closed loop control. A maximum impact load of $100 \mathrm{kN}$ can be achieved in the testing system. The room temperature during the test was about $30^{\circ} \mathrm{C} \pm 3^{\circ} \mathrm{C}$.

The Instron VHS system comprises a fast jaw grip, which accelerates in the direction of tension till the designed testing velocity is achieved. A pre-set wedge is kicked out to release the sprung grips which firmly grab the upper tap and pull the specimen at the designed testing velocity until its fracture. A piezo load cell is installed below the bottom grip head to monitor the force that the specimen experienced. An accelerometer was built on the fast jaw to measure its acceleration. In the tests, an extensometer in the fast jaw was utilized to track the stroke of the actuator. A strain gauge the same as that used in the quasi-static test was glued to the center of each specimen to measure its strain. All signals of the above transducers were connected to a data acquisition system with a sampling frequency of $65 \mathrm{kHz}$. A high-speed camera (Fastcam SA1.1 by Photron ${ }^{\circledR}$ ) was installed to monitor the dynamic fracture process of the CFRP laminates. It was trigger by a TTL pulse from the 
1 Instron testing system. The lighting for high-speed film was provided by a $2000 \mathrm{w}$ halogen

2 light (Leiying ${ }^{\circledR} \mathrm{M} 300 \mathrm{G}$ ). The filming frequency was set to $30,000 \mathrm{fps}$. In the dynamic tests,

3 actuator speeds were varied from $1 \mathrm{~m} / \mathrm{s}$ to $20 \mathrm{~m} / \mathrm{s}$. The strain rates of about $10 \mathrm{~s}^{-1}$ to $240 \mathrm{~s}^{-1}$

4 were achieved. Table 2 lists the detailed specimen configurations and high-speed tensile test 5 parameters.

\section{Testing Results}

\subsection{Quasi-static and low-speed test results}

\subsubsection{Crosshead displacement vs. strain gauge}

Figure 5 shows a sample strain time history measured from strain gauge glued directly onto the CFRP coupon and that derived from actuator crosshead displacement (displacement divided by central testing gauge length). It can be found that the measured strain differs significantly from that derived from the crosshead displacement, and the divergence becomes more and more apparent with time. A failure strain of about $1.065 \%$ was measured by the strain gauge. In comparison, an ultimate strain of $1.571 \%$ can be derived from the crosshead displacement data, which is $47 \%$ higher than the actual strain measured on the specimen directly. This variation is mainly attributed to the large stiffness of the CFRP/epoxy laminates which makes the deformation of the testing machine no longer negligible. Therefore, in this study measurement from strain gauge is utilized to evaluate the strain of the CFRP/epoxy laminates. The secant slope of the strain time history is adopted to define the averaged strain rate that the material experienced.

\subsubsection{Stress-strain curves}

Figure 6 and Figure 7 show the typical CFRP coupon and carbon fiber stress-strain curves at representative strain rates in the quasi-static and low-speed tensile tests. Because of the very low tensile strength of the epoxy as compared to that of fibre, only the fiber thickness is considered when determining the fiber stress. As can be observed, under quasi-static tensile loading, the CFRP specimens behave essentially as a linear elastic material until the point of failure. At a strain rate of $8 \times 10^{-5} \mathrm{~s}^{-1}$, an ultimate coupon stress of $667 \mathrm{MPa}$ is measured, which corresponds to the fiber strength of $2953 \mathrm{MPa}$. As loading rate increases, the tensile strength appears to increase. At a strain rate of $8 \times 10^{-4} \mathrm{~s}^{-1}$, the coupon strength and fiber strength increase to $716 \mathrm{MPa}$ and $3062 \mathrm{MPa}$, respectively. The corresponding failure strain reduces marginally from $1.09 \%$ to about $1.06 \%$. Nevertheless, the increase in specimen strength is not continuous and stable with the increase of strain rate. When strain rates go up to $4 \times 10^{-}$ 
$1 \mathrm{~s}^{3}$ and then further to $7.7 \times 10^{-3} \mathrm{~s}^{-1}$, there is no significant increase in coupon strength and

2 fiber strength. The complete results of the quasi-static and low-speed tests on CFRP/epoxy

3 laminates obtained in the tests are listed in Table 3.

\subsection{High-speed test results}

High-speed tensile testing results are presented in this section. The difficulties in successfully carrying out dynamic test especially at high strain rates are from the existence of inertia effect due to the mass of the tap, clamp, and the specimen itself etc., as well as the reliability of the testing system which may result in system ringing [15] and etcetera. Therefore, in the following section validation of dynamic test and evaluation on inertia effect is firstly provided, which is then followed by detailed dynamic testing results.

\subsubsection{Validation of high-speed test}

To obtain valid testing data from dynamic test, the condition of dynamic equilibrium needs to be carefully checked. It is necessary to ensure there is sufficient number of stress reverberation within the specimen before failure occurs. If an averaged Young's modulus of 679MPa for CFRP coupon from quasi-static test and a density of $1.8 \mathrm{~g} / \mathrm{cm}^{3}$ are substituted into Eq. (2), the longitudinal wave velocity in the CFRP coupon is about $614 \mathrm{~m} / \mathrm{s}$. It requires about $80 \mu \mathrm{s}$ for the stress wave to propagate through the $5 \mathrm{~cm}$ long testing gauge. At a actuator velocity of $1 \mathrm{~m} / \mathrm{s}$, CFRP specimen fractures at about $2200 \mu \mathrm{s}$, which allows the stress wave to travel through the specimen for more than 20 times. At the maximum pulling velocity of $20 \mathrm{~m} / \mathrm{s}$ in the current test, the fracture time (nearly $400 \mu \mathrm{s}$ ) still enables the stress wave to travel through for 5 times. Therefore, it is confident to believe that dynamic stress equilibrium can be achieved in the current test and the testing data is reliable.

The response of the whole testing system also needs to be examined, which includes the nature period of the grip, tab and the load cell. If the nature period of the testing system is not short enough than the rising time of the force on the CFRP specimen, the load cell may not properly track the true applied force due to machine and specimen interaction. A typical load time history after a specimen fractures is shown in Figure 9. It can be estimated that the oscillation period of the system is around $194 \mu \mathrm{s}$. When the actuator is pulling at $1 \mathrm{~m} / \mathrm{s}$, it takes about $2200 \mu$ s for the specimen to break, which is much longer than the response of the testing system. When the actuator reaches the maximum pulling velocity of $20 \mathrm{~m} / \mathrm{s}$, the rising time for the specimen to fracture is nearly $400 \mu \mathrm{s}$, which is approaching the practical limit for the load cell to track the response of the tested specimen [17]. 
A typical load time history recorded by the load cell is presented in Figure 9. The load measured by the load cell includes both the response of material and the inertia force. To quantify inertia force, the acceleration time history traced by the accelerometer in the fast jaw is multiplied by the mass of the clamping tabs and the CFRP/epoxy coupons. As can be seen in Figure 9, the contribution of the inertia force is not significant as compared with the total measured load. This is mainly due to the high strength of the CFRP material. Nevertheless, in processing the testing data the inertia force is deducted from the recorded total load so as to obtain accurate material response. Figure 10 shows the corrected load time history after removing the inertia force at several different strain rates. The time axis is aligned. Noticeable difference on the peak loads can be observed on the specimens tested at different strain rates. The strength of the CFRP specimens is obviously strain rate sensitive.

\subsubsection{Stress-strain curves}

The CFRP coupon and carbon fiber stress-strain curves at different strain rates in the high-speed tensile tests are shown in Figure 11 and Figure 12. It can be observed that under dynamic tensile loading, the CFRP coupons show elastic behavior. Stress increases almost linearly with strain at the beginning. When the strain approaches failure strain, the stiffness increases slightly indicating minor non-linear behavior. The plot also reflects that the response of CFRP laminates is strain rate dependent. At a strain rate of $11 \mathrm{~s}^{-1}$, an ultimate coupon stress of $717 \mathrm{MPa}$ is reached which corresponds to fiber strength of $2985 \mathrm{MPa}$. As strain rate increases, both coupon strength and fiber strength increase. At a strain rate of $185 \mathrm{~s}^{-1}$, the coupon strength rises to about $861 \mathrm{MPa}$ with fiber strength $5009 \mathrm{MPa}$, which reflects an increment of $20 \%$. When strain rate increases to $234 \mathrm{~s}^{-1}$, the coupon strength and fiber strength go up to $955 \mathrm{MPa}$ and $5506 \mathrm{MPa}$, indicating a $33 \%$ increment. Detailed highspeed testing data are listed in Table 4.

\section{Analysis and Discussions}

\subsection{Strain rate effect on tensile strength}

Dynamic testing results in Section 4 show apparent strain rate effect on material tensile strength. The tested CFRP/epoxy coupon strength in the quasi-static tests and the dynamic tests are summarized and plotted against respective strain rate that the material experienced in Figure 13. Available testing data reported by other researchers in the literatures on CFRP/epoxy laminates are also included for analysis. As shown in Figure 13, 
1 the CFRP coupon strengths in the current tests are consistent. The coupon strength does not show much variation with strain rate under quasi-static loading and at low-strain rates.

3 Significant increase in coupon strength can be found when strain rate is over approximately $450 \mathrm{~s}^{-1}$, which rises quickly with strain rate. The current group of testing data agrees with that from Mak [18] and Zhao et al. [6]. It also shows similar increasing trend with the data from Welsh and Harding [5]. However, the coupon strength reported by Welsh and Harding are much lower than that from the current study. This is believed to be due to different CFRP materials tested in the two studies. The coupon strengths tested by Orton et al. [19] show very large variation. Typical coupon strengths in [19] vary from about $600 \mathrm{MPa}$ to nearly $1200 \mathrm{MPa}$. This is possibly due to the quality in preparing the testing specimens.

The fiber strength versus strain rate relationship is plotted in Figure 14. It is worth noting that the fiber strength derived herein is from the load measured on CFRP/epoxy laminates. The contribution of epoxy strength is neglected. Similar simplification was also adopted by many other researchers $[9,20]$. The error introduced with this simplification is quite small because the tensile strength of the epoxy resin used in the study is only about 20MPa. The maximum load taken by the epoxy is estimated to be merely $0.235 \mathrm{kN}$ (estimated by $0.469 \mathrm{~mm}$ ( $0.6 \mathrm{~mm}$ coupon thickness minus $0.131 \mathrm{~mm}$ fiber thickness) $\times 25 \mathrm{~mm}$ (average coupon width) $x 20 \mathrm{MPa}$ epoxy strength). Comparing with the load taken by carbon fiber, the proportion of load taken by epoxy is less than $3 \%$. Therefore, the influence of ignoring the load taken by epoxy is minor. From Figure 14 it can be seen that at low-strain rate, the strength of carbon fiber does not show much strain rate dependency. But as strain rate goes above $50 \mathrm{~s}^{-1}$, fiber strength begins to increase significantly with strain rate. The averaged fiber strength increases from about $3400 \mathrm{MPa}$ at a strain rate of about $50 \mathrm{~s}^{-1}$ to about $5200 \mathrm{MPa}$ at strain rate around $200 \mathrm{~s}^{-1}$. The two groups of testing data reported by Al Zubaidy et al. $[9,20]$ show similar trend as the current testing results. The testing results on CFRP cables (without epoxy resin) also indicates similar trend that fiber strength increases insignificant from $2210 \mathrm{MPa}$ to $2250 \mathrm{MPa}$ when strain rate is below $0.01 \mathrm{~s}^{-1}$, but exhibits noticeable increment with a tensile strength of $2600 \mathrm{MPa}$ at a strain rate of $100 \mathrm{~s}^{-1}$. The fiber strengths reported by Kimura et al. [21] also show strain rate dependency, but it only reaches a maximum strain rate of $100 \mathrm{~s}^{-1}$. The results from Taniguchi et al. [10] do not show any strain rate dependency. But their testing data only cover a very narrow strain rate range. It is therefore difficult to assert the possible reasons. 
Figure 15 presents the failure strain as a function of strain rate. The failure strains in the

2 low-strain rate range of the current study are around $1.0 \%$. Similarly to the relationship between the strength and strain rate above, the failure strain in the low-strain rate range does not show much correlation with strain rate. When strain rate increases beyond $50 \mathrm{~s}^{-1}$, apparent higher failure strain can be observed, which also increases with strain rate. The correlation of failure strain and strain rate agrees with the testing results by Al Zubaidy et al. $[9,20]$. The failure strains reported by Kimura et al. [21] also fall in the range of the current group of tests. The failure strains from Welsh and Harding [5] are much higher than the others' data which is probably because of different type of CFRP tested.

\subsection{Strain rate effect on coupon stiffness and fiber modulus}

The coupon stiffness and the corresponding strain rate are plotted in Figure 16. The average coupon stiffness in the low-strain rate range is about 50GPa, which does not show much strain rate dependency. As strain rate goes over $10 \mathrm{~s}^{-1}$, the coupon stiffness shows an increasing trend with respect to the increase of strain rate. The increasing trend of coupon stiffness over strain rate shows consistency with previous testing result obtained by Harding and welsh [5] and by Zhao [6], but very different from those obtained by Orton, et al. [19].

As for the fiber modulus (Figure 17), more consistent testing data and clear dynamic increase effect can be found in the high-strain rate range, while in the low-strain rate region fiber modulus appears to be steady with the increase of strain rate. Similar dynamic amplification effect on fiber modulus can also be found from the testing data reported by previous researchers $[9,20,21]$. However, the fiber modulus reported in reference [10] appears to be insensitive to strain rate, but only limited strain rates are covered in [10].

\subsection{Dynamic failure process}

The above testing data and analysis show noticeable strain rate effect on CFRP material properties especially in the high-strain rate range. Both the coupon strength and fiber strength are found to increase at high strain rate. The corresponding failure strain is also found to increase with strain rate. However, the increase in material strength and failure strain are not proportional. Instead, based on analysis on coupon stiffness and fiber modulus it can be found that the material strength is increasing faster than failure strain, implying the elastic modulus is also sensitive to strain rate.

Based on testing data obtained by different researchers, different conclusions regarding the dynamic increase effect on CFRP strength have been drawn. On one hand, some researchers 
1 believe this is a character of material property that the strength of CFRP material itself is strain rate dependent. More specifically, carbon fiber is a brittle material similar to glass [14, 22]. The fracture of carbon fiber strongly depends on the initiation and propagation of the existing micro-cracks [5]. At high strain rate, there is no sufficient time for crack to grow, which as a result leads to higher material strength. On the other hand, some others attribute the increment in strength in dynamic testing to a structural response. For instance, Gilat et al. [8] explained the increase in CFRP laminate strength is a result of the confinement from epoxy resin. Welsh and Harding also pointed out that the woven structure and interaction between CFRP and epoxy matrix are the two possible reasons leading to the elevated strength measured. There is no consensus yet at this stage. In the current study, high-speed camera images of the dynamic failure process of CFRP/epoxy laminates are analyzed to examine the reasons leading to the dynamic increase effect. The failure processes of CFRP specimens at relatively low-strain rate $\left(\dot{\varepsilon}=43 \mathrm{~s}^{-1}\right)$ and high-strain rate $\left(\dot{\varepsilon}=234 \mathrm{~s}^{-1}\right)$ are provided below.

Figure 18 shows the dynamic failure process of CFRP at a strain rate of $43 \mathrm{~s}^{-1}$. As shown, at $t=500 m s$ epoxy fractures initiate due to their low failure strain. At $t=567 \mathrm{~ms}$ carbon fiber cracks begin to form and develop. A critical crack is formed at about $t=900 \mathrm{~ms}$ when the CFRP specimen splits into halves. In comparison, Figure 19 depicts the failure process of the CFRP specimen tested at a strain rate of $234 \mathrm{~s}^{-1}$. Similar to the low-strain rate tensile test, epoxy fractures can be spotted at an earlier stage of the test ( $t=100 \mathrm{~ms})$. At $t=133 \mathrm{~ms}$, more epoxy fractures can be found throughout the CFRP specimen. Fiber crack initiates at about $167 \mathrm{~ms}$. To be different from that in the low-strain rate test, two diagonal major cracks are formed instead of a single critical crack at the gauge center. The CFRP specimen eventually splits into three segments by the two diagonal cracks together with numerous fragments. The highspeed camera images on the dynamic failure process of CFRP specimens depict two different failure modes. Under low-strain rate unidirectional tension, CFRP specimen fails by tensile failure of carbon fiber near the center of the gauge. At high-strain rate, the failure of CFRP specimen is formed by multiple diagonal shear planes among the specimen. Figure 20 shows the failure patterns of CFRP specimens involved in the quasi-static and dynamic tensile tests. As can be observed, the specimens tested at low-strain rates in general fail with a single critical fracture perpendicular to the loading direction around gauge centers, while those in high-strain rate tests are normally associated with diagonal cracks and multiple failure planes. Comparing with the single cross-sectional fracture mode, the failure mode with 
1 diagonal cracks consumes more imposed energy, which as a result leads to higher material

2 strength.

35.5 Dynamic increase factor and empirical formulae

4 Dynamic increase factor (DIF), as a ratio of dynamic strength over quasi-static strength, 5 can be employed to represent the increase in material strength at various strain rates. The 6 measured coupon strengths in the current study are normalized against the average coupon 7 strength at quasi-static state $\left(7.8 \times 10^{-5} \mathrm{~s}^{-1}\right)$ to derive the DIF for coupon strength. Together 8 with previous testing data, the DIF of CFRP coupon strength is plotted against strain rate in

9 Figure 21. The trend of DIF for coupon strength of this study shows consistency with most 10 previous testing results. The DIF for coupon strength can be approximately modelled by the 11 following empirical equations

$$
\begin{array}{ll}
D I F_{\text {coupon }}=0.012 \log _{10}(\dot{\varepsilon})+1.014 & \dot{\varepsilon}<50 \mathrm{~s}^{-1} \\
D I F_{\text {coupon }}=0.445 \log _{10}(\dot{\varepsilon})+0.293 & \dot{\varepsilon} \geq 50 \mathrm{~s}^{-1}
\end{array}
$$

12 where $\dot{\varepsilon}$ is the strain rate.

Figure 22 presents the DIF for CFRP fiber strength versus strain rate. A quite consistent trend can also be found between the DIF derived from the current tests and those from other researchers'. The relationship between DIF for carbon fiber strength and strain rate can be expressed as follows

$$
\begin{aligned}
& D I F_{\text {fiber }}=0.0001 \log _{10}(\dot{\varepsilon})+1.003 \quad \dot{\varepsilon}<50 s^{-1} \\
& D I F_{\text {fiber }}=1.095 \log _{10}(\dot{\varepsilon})-0.857 \quad \dot{\varepsilon} \geq 50 s^{-1}
\end{aligned}
$$

where $\dot{\varepsilon}$ is the strain rate.

\section{Conclusions}

In this study, laboratory tests were performed to investigate the static and dynamic material properties of CFRP/epoxy laminates. The testing results indicate that the mechanical properties of CFRP/epoxy laminates are strain rate dependent. Both its tensile strength and failure strain are found to increase significantly when strain rate is above $50 \mathrm{~s}^{-1}$. The coupon stiffness is also found to be strain rate sensitive at high-strain rate range. The material properties of carbon fiber including tensile strength, failure strain and tensile modulus are found to show strain rate dependency when strain rate is high. However, under quasi-static 
or low-speed tensile loading, there is not much noticeable increase in either aspect of mechanical properties. The high-speed camera images depict that the increase in material strength is probably because of the different failure mode at high-strain rate comparing with that at low-strain rate. Diagonal cracks with multiple failure planes tend to be formed in CFRP specimens tested at high-strain rates. Empirical formulas of DIF for CFRP/epoxy laminates and carbon fiber strengths are derived based on testing results.

\section{Acknowledgement}

The authors would like to thank Australia Research Council for financial support. The first author would also like to acknowledge the contribution of Mr. Konrad Robertson from the University of Western Australia to the laboratory test.

\section{Reference}

[1] G.C. Jacob, J.M. Starbuck, J.F. Fellers, S. Simunovic, R.G. Boeman, Strain rate effects on the mechanical properties of polymer composite materials, Journal of Applied Polymer Science, vol. 94 (2004), pp. 296-301.

[2] R. Sierakowski, Strain rate effects in composites, Applied Mechanics Reviews, vol. 50 (1997), pp. 741-761.

[3] J. Hou, C. Ruiz, Measurement of the properties of woven CFRP T300/914 at different strain rates, Composites Science and Technology, vol. 60 (2000), pp. 2829-2834.

[4] M. Wisnom, Size effects in the testing of fibre-composite materials, Composites Science and Technology, vol. 59 (1999), pp. 1937-1957.

[5] L. Welsh, J. Harding, Effect of strain rate on the tensile failure of woven reinforced polyester resin composites, Le Journal de Physique Colloques, vol. 46 (1985), pp. C5-405C405-414.

[6] G.P. Zhao, Z.H. Wang, J.X. Zhang, Q.P. Huang, Modeling and Testing Strain RateDependent Tensile Strength of Carbon/Epoxy Composites, Key Engineering Materials, vol. 353 (2007), pp. 1418-1421.

[7] X. Chen, Y. Li, Z. Zhi, Y. Guo, N. Ouyang, The compressive and tensile behavior of a 0/90 C fiber woven composite at high strain rates, Carbon, vol. 61 (2013), pp. 97-104.

[8] A. Gilat, R.K. Goldberg, G.D. Roberts, Experimental study of strain-rate-dependent behavior of carbon/epoxy composite, Composites Science and Technology, vol. 62 (2002), pp. 1469-1476.

[9] H. Al-Zubaidy, X.-L. Zhao, R. Al-Mahaidi, Mechanical characterisation of the dynamic tensile properties of CFRP sheet and adhesive at medium strain rates, Composite Structures, vol. 96 (2013), pp. 153-164.

[10] N. Taniguchi, T. Nishiwaki, H. Kawada, Tensile strength of unidirectional CFRP laminate under high strain rate, Advanced Composite Materials, vol. 16 (2007), pp. 167-180. [11] X. Zhang, Y. Shi, H. Hao, J. Cui, The Mechanical Properties of lonoplast Interlayer Material at High Strain Rates, Materials \& Design, vol. 83 (2015), pp. 387-399.

[12] X. Zhang, H. Hao, Y. Shi, J. Cui, The Mechanical Properties of Polyvinyl Butyral (PVB) for Laminated Glass at High Strain Rates, Construction and Building Materials, vol. 93 (2015), pp. 404-415.

[13] W.N. Sharpe Jr, W.N. Sharpe, Springer handbook of experimental solid mechanics, Springer, 2008. 
1 [14] X. Zhang, Y. Zou, H. Hao, X. Li, G. Ma, K. Liu, Laboratory Test on Dynamic Material 2 Properties of Annealed Float Glass, International Journal of Protective Structures, vol. 3 3 (2012), pp. 407-430.

4 [15] X. Xiao, Dynamic tensile testing of plastic materials, Polymer Testing, vol. 27 (2008), pp. $5 \quad 164-178$.

6 [16] ASTM D3039/D3039M-07, Standard Test Method for Tensile Properties of Polymer 7 Matrix Composite Materials, West Conshohocken, PA, 2008.

8 [17] P. Hooper, B. Blackman, J. Dear, The mechanical behaviour of poly (vinyl butyral) at 9 different strain magnitudes and strain rates, Journal of Materials Science, vol. 47 (2012), pp. 10 3564-3576.

11 [18] Y.-P. Mak, Strain Rate Effects on Tensile Fracture and Damage Tolerance of Composite Laminates, Department of Aeronautics and Astronautics, Massachusetts Institute of Technology, US, 1990.

[19] S.L. Orton, V.P. Chiarito, C. Rabalais, M. Wombacher, S.P. Rowell, Strain Rate Effects in CFRP Used For Blast Mitigation, Polymers, vol. 6 (2014), pp. 1026-1039.

[20] H. Al-Zubaidy, X.-L. Zhao, R. Al-Mihaidi, Mechanical behaviour of normal modulus carbon fibre reinforced polymer (CFRP) and epoxy under impact tensile loads, Procedia Engineering, vol. 10 (2011), pp. 2453-2458.

[21] H. Kimura, M. Itabashi, K. Kawata, Mechanical characterization of unidirectional CFRP thin strip and CFRP cables under quasi-static and dynamic tension, Advanced Composite Materials, vol. 10 (2001), pp. 177-187.

[22] X. Zhang, H. Hao, G. Ma, Dynamic material model of annealed soda-lime glass, International Journal of Impact Engineering, vol. 77 (2015), pp. 108-119. 


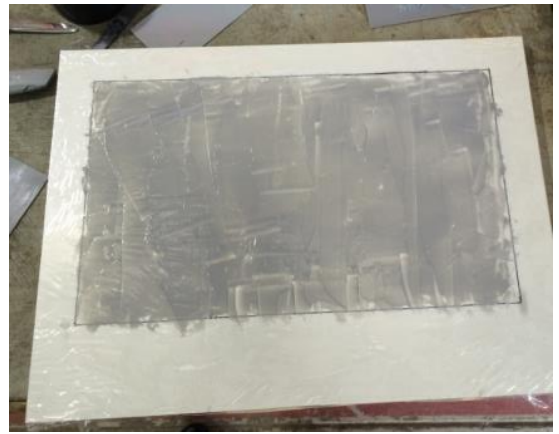

a) Spread epoxy on base board

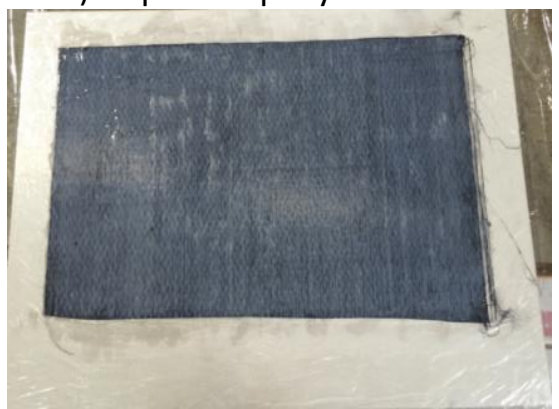

c) Roll epoxy on the top of fiber wrap

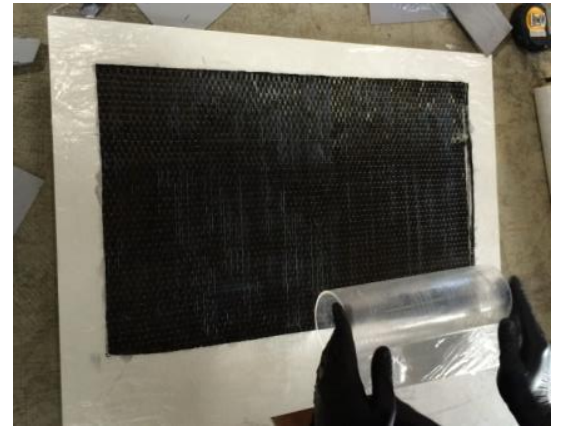

b) Lay fiber wrap and roll with roller

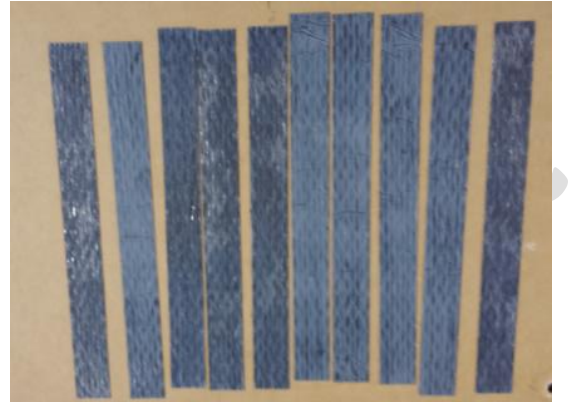

d) Cut cured laminates into strips

Figure 1 Preparation of CFRP/epoxy laminate sheets

2 

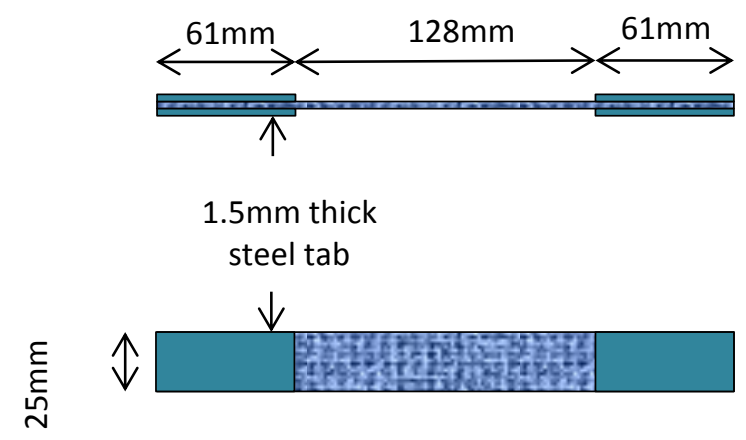

a) Schematic view of coupon for quasi-static and low-speed test

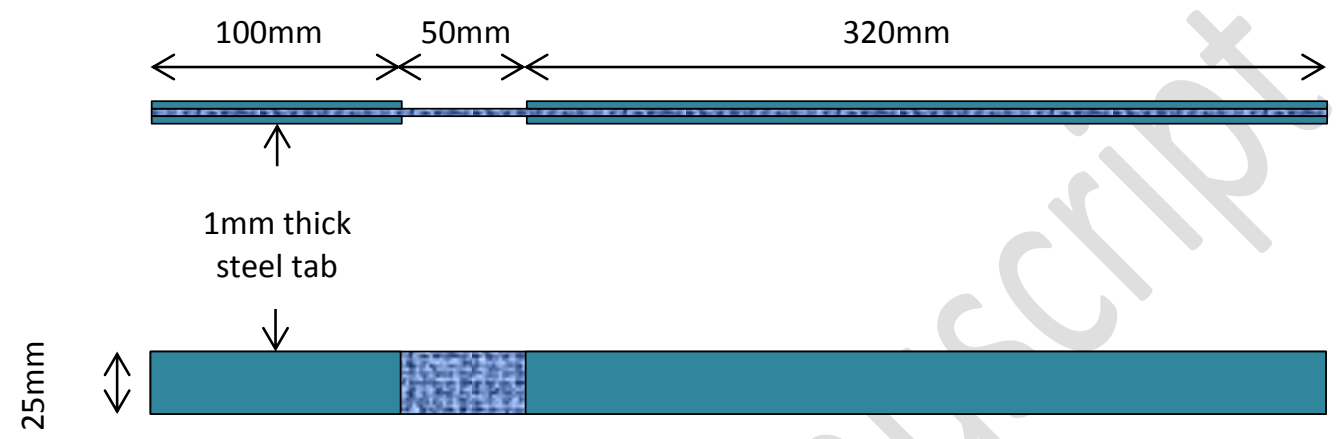

b) Schematic view of coupon for high-speed test

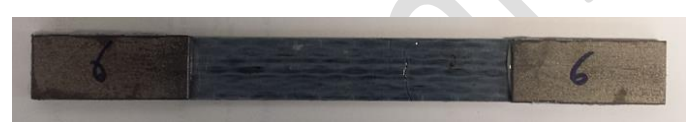

c) Sample CFRP coupon for quasi-static and low-speed test

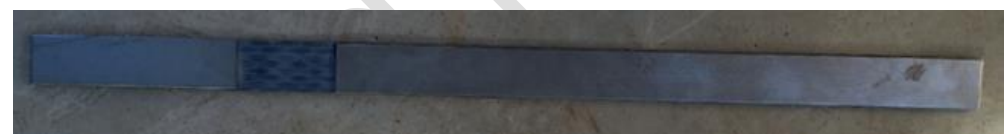

d) Sample CFRP coupon for high-speed test

Figure 2 Schematic views of coupons for quasi-static and dynamic tests

2 


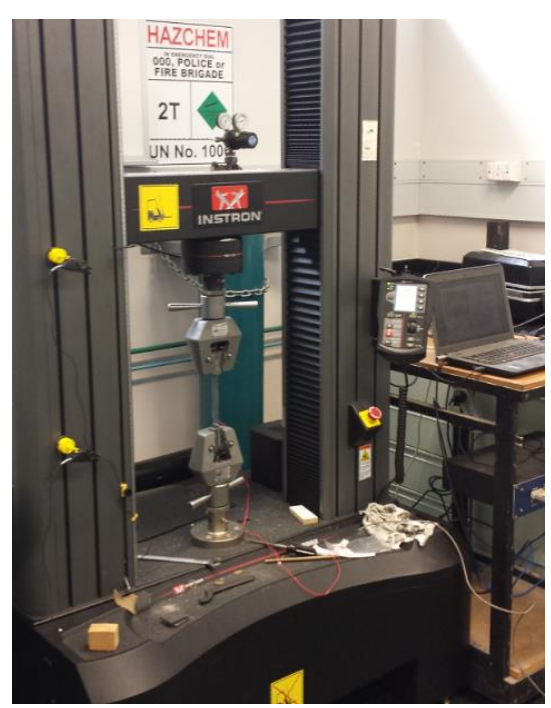

a) Test setup

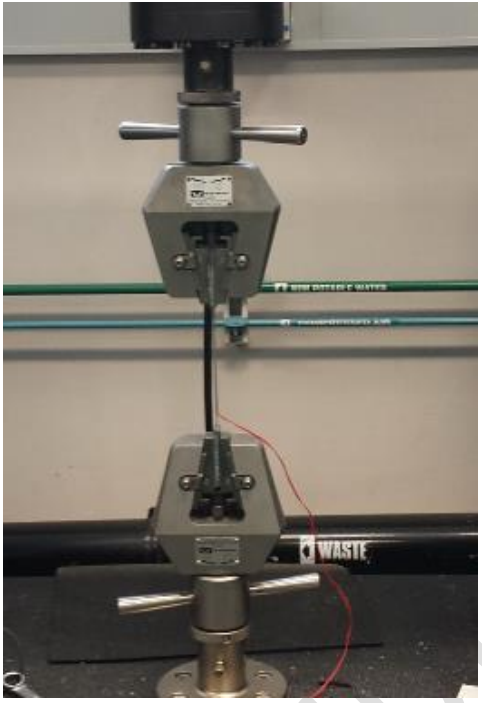

b) Detail of clamp and specimen

Figure 3 Instron UTS-5982 hydraulic machine and test setup

2 


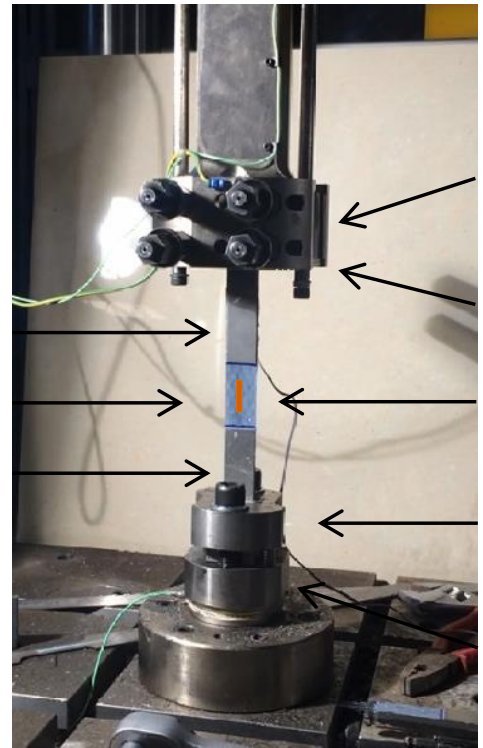

Knock-out wedge

Fast jaw

Strain gauge

Lower tap

Figure 4 High-speed tensile test setup

2 


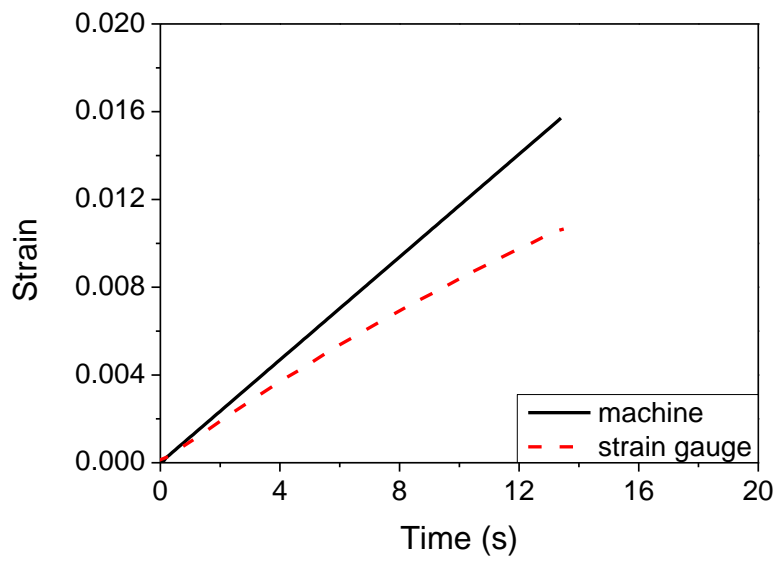

1

Figure 5 Sample strain time histories measured by strain gauge and derived from crosshead displacement

4 


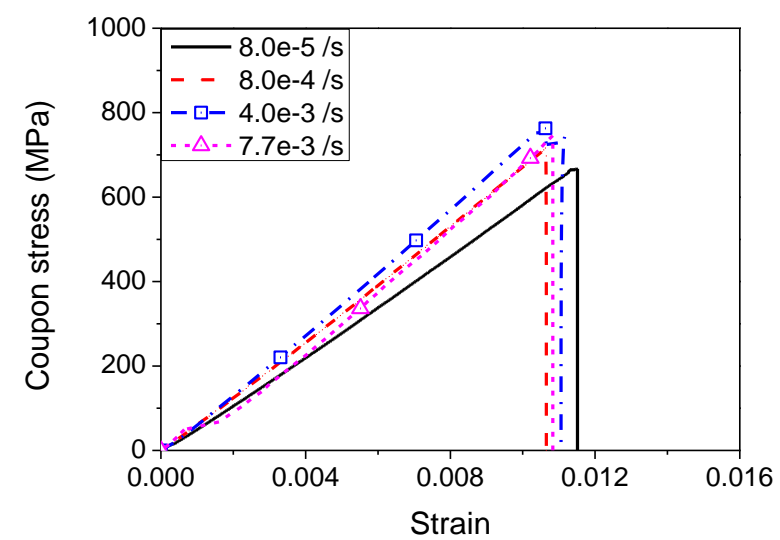

1

2 Figure 6 Typical coupon stress-strain curves at various strain rates in quasi-static and low-

3 speed tests

4 


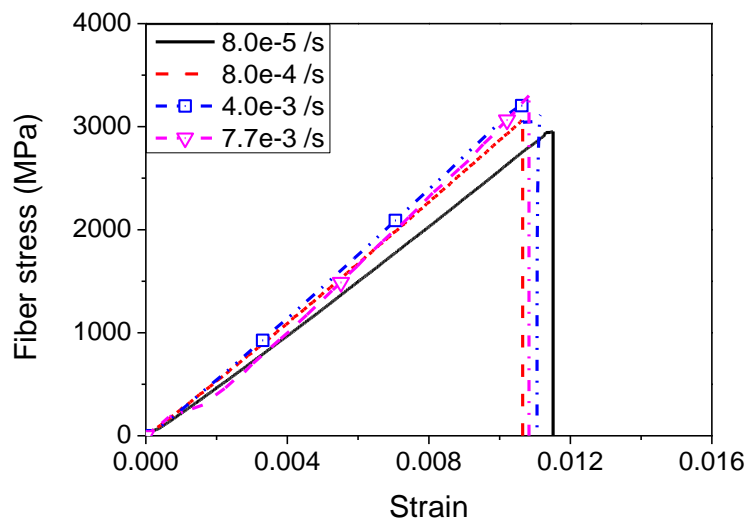

1

2 Figure 7 Typical fiber stress-strain curves at various strain rates in quasi-static and low-speed 3 tests 


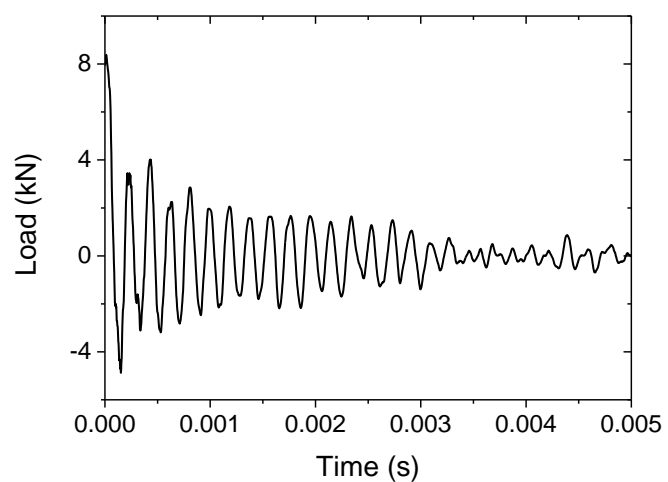

2

Figure 8 Free vibration of the Instron VHS testing system after a specimen fractures

3 


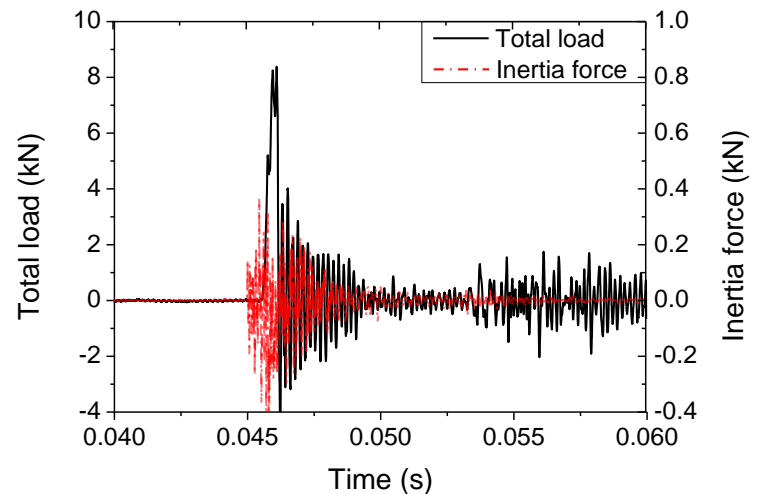

2

Figure 9 Load time histories of total load and inertia force

4 


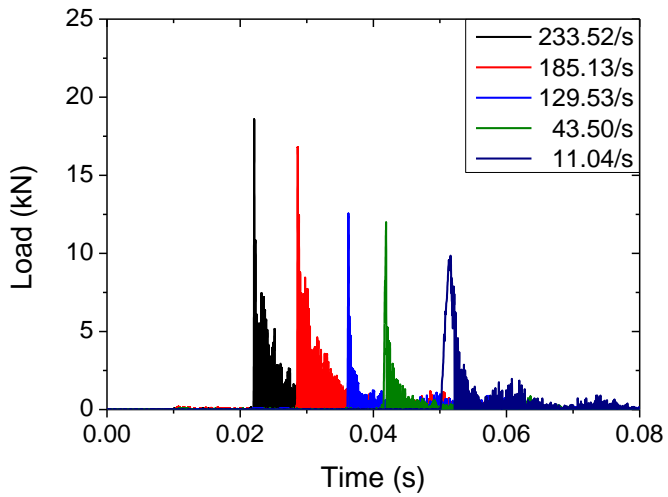

Figure 10 Typical pure load time histories at different strain rates

3 


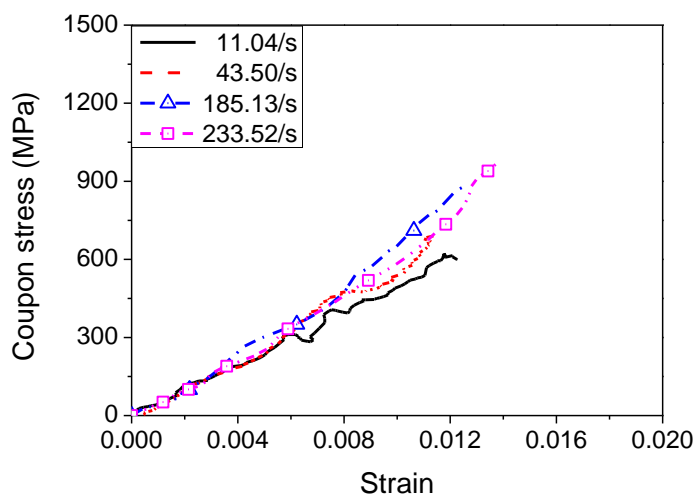

2

Figure 11 Typical coupon stress-strain curves at various strain rates in dynamic tests

3 


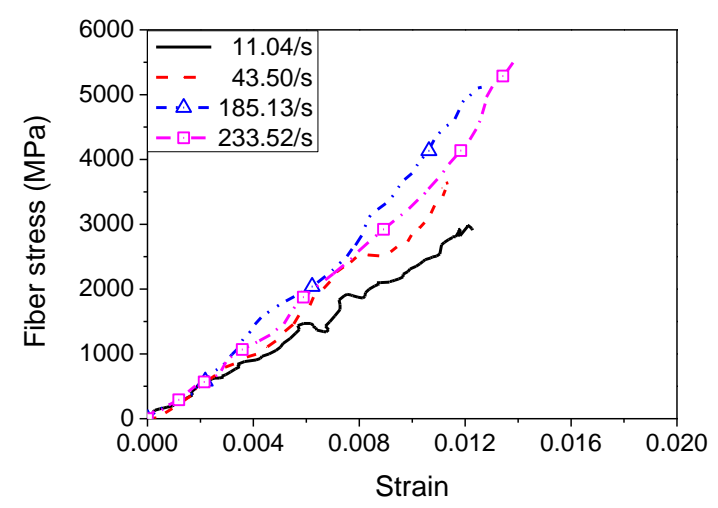

1

Figure 12 Typical fiber stress-strain curves at various strain rates in dynamic tests

3 


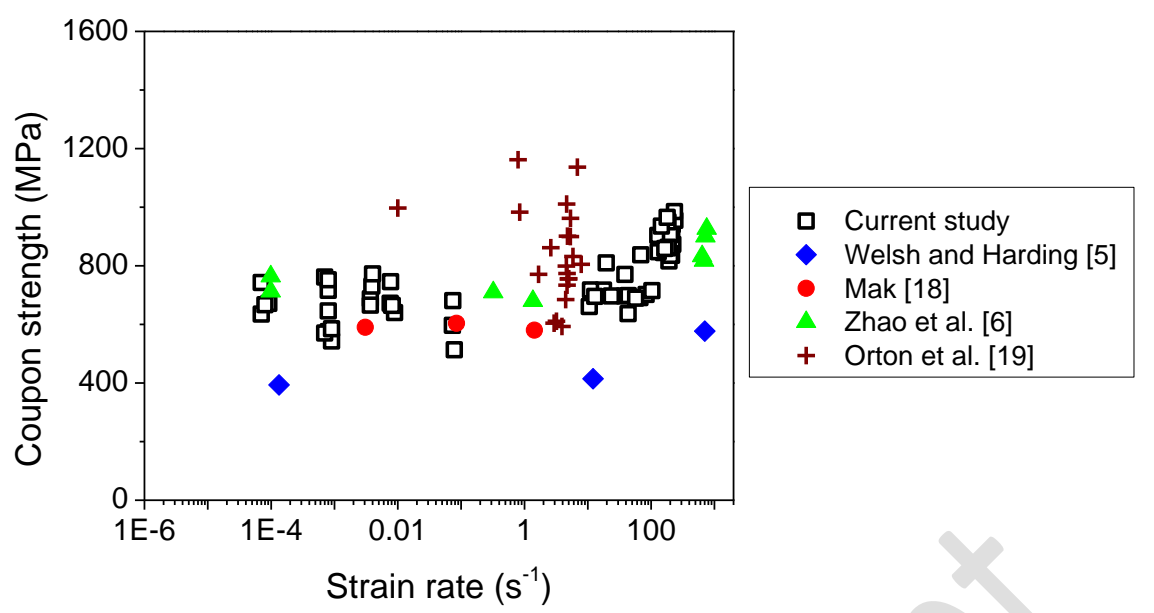

Figure 13 Coupon strength versus strain rate

3 


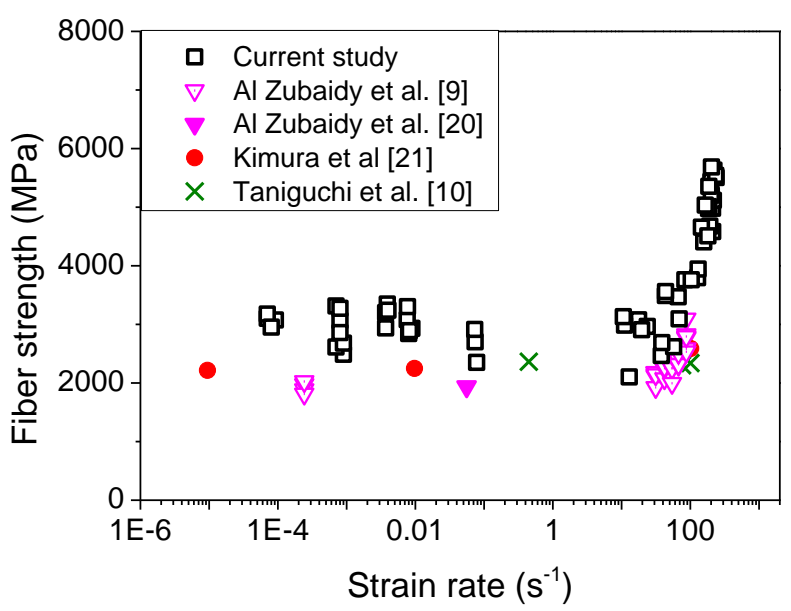

Figure 14 Carbon fiber strength versus strain rate 3 


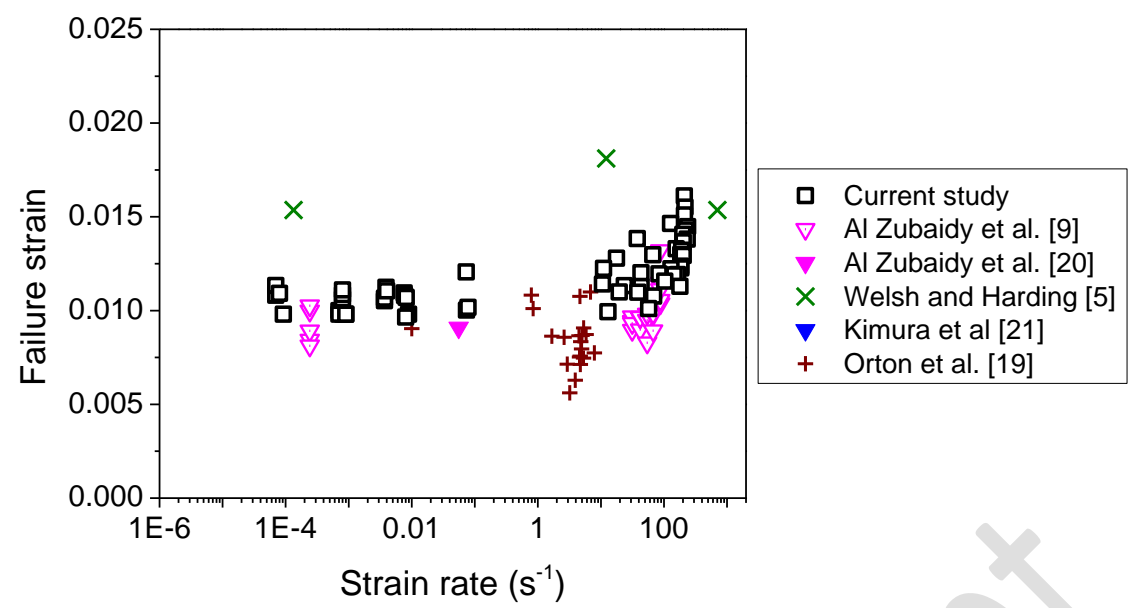

2

Figure 15 Failure strain versus strain rate

3 


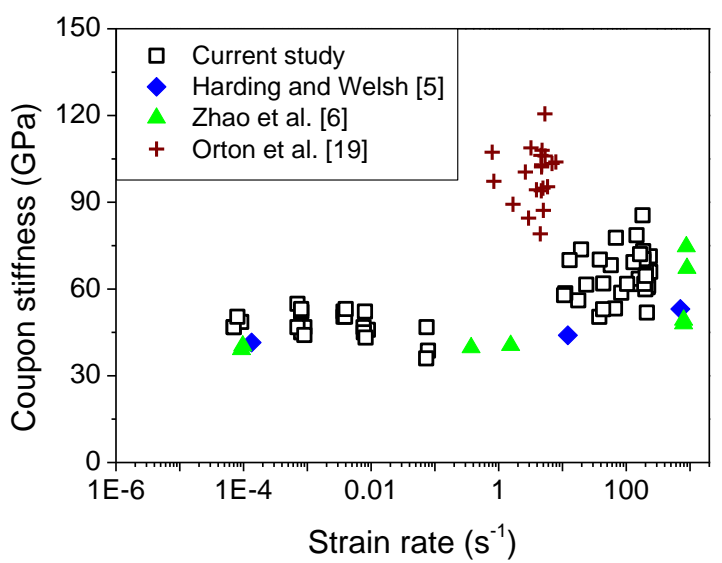

Figure 16 Coupon stiffness versus strain rate

3 


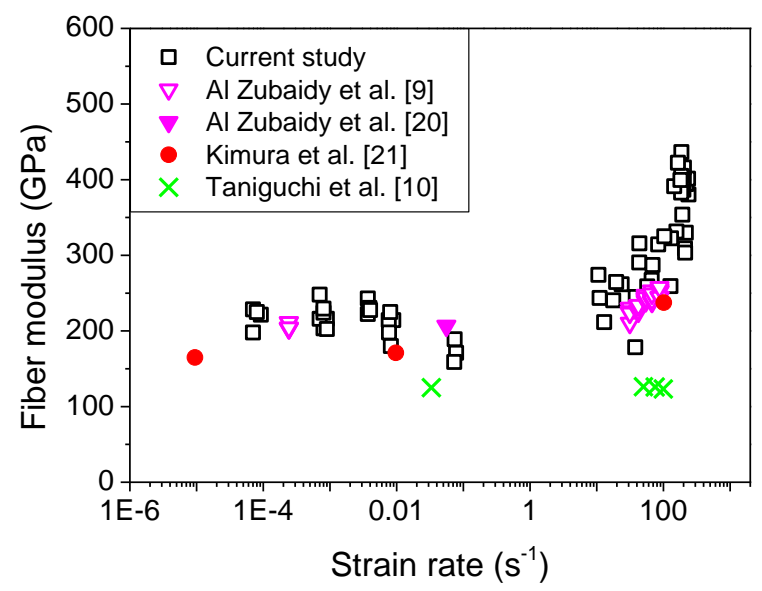

2

Figure 17 Fiber modulus versus strain rate

3 


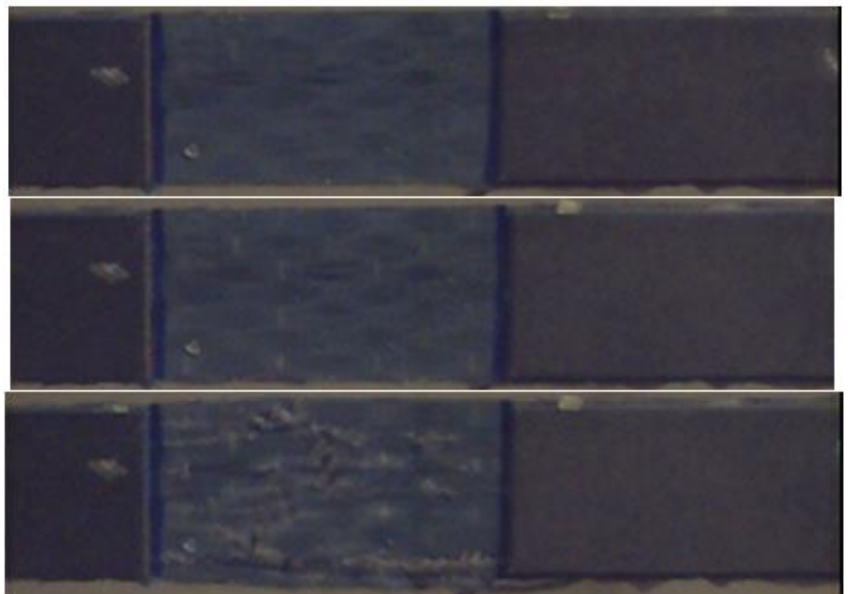

$\mathrm{T}=0 \mu \mathrm{s}$

$\mathrm{T}=500 \mu \mathrm{s}$

$\mathrm{T}=567 \mu \mathrm{s}$

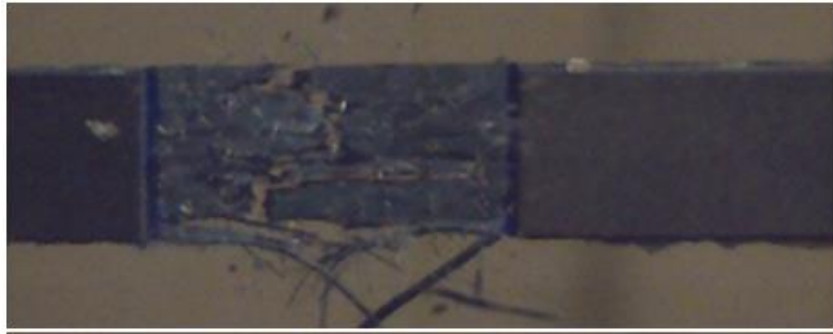

$\mathrm{T}=900 \mu \mathrm{s}$

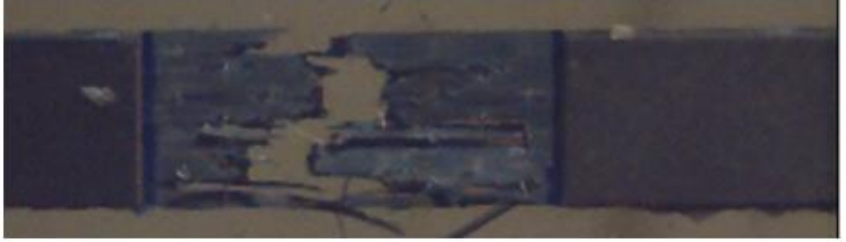

$\mathrm{T}=2667 \mu \mathrm{s}$

2

3

4

5

Figure 18 High-speed camera images of CFRP specimen failure process at a strain rate of $43 s^{-1}$ 


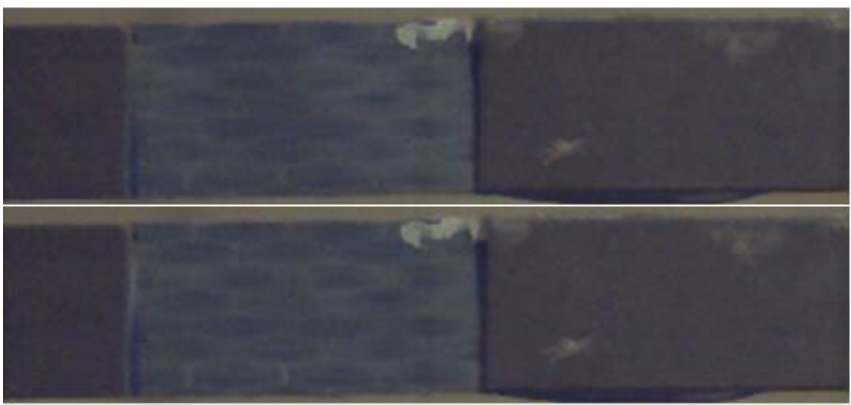

$\mathrm{T}=0 \mu \mathrm{s}$

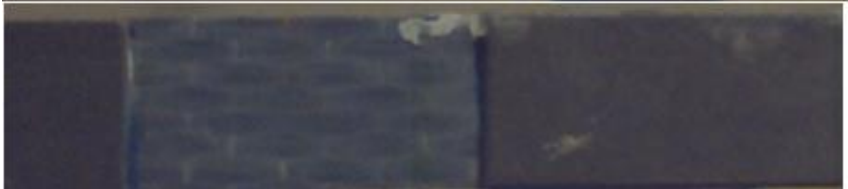

$\mathrm{T}=133 \mu \mathrm{s}$

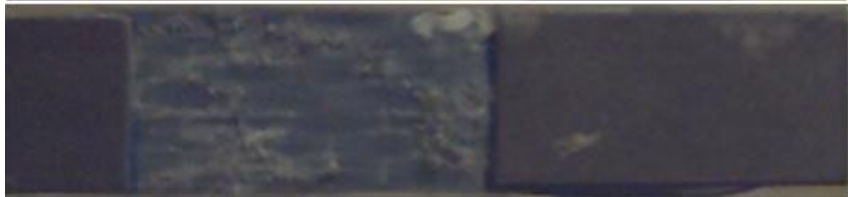

$\mathrm{T}=167 \mu \mathrm{s}$

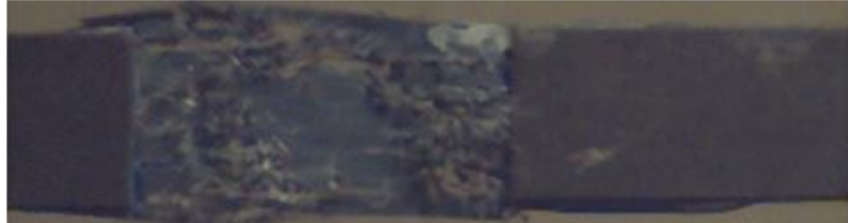

$\mathrm{T}=233 \mu \mathrm{s}$

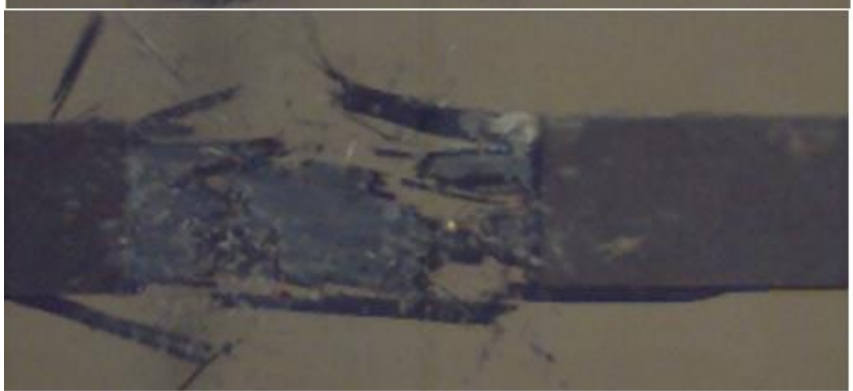

$\mathrm{T}=467 \mu \mathrm{s}$

2

Figure 19 High-speed camera images of CFRP specimen failure process at a strain 3 rate of $234 s^{-1}$

4 


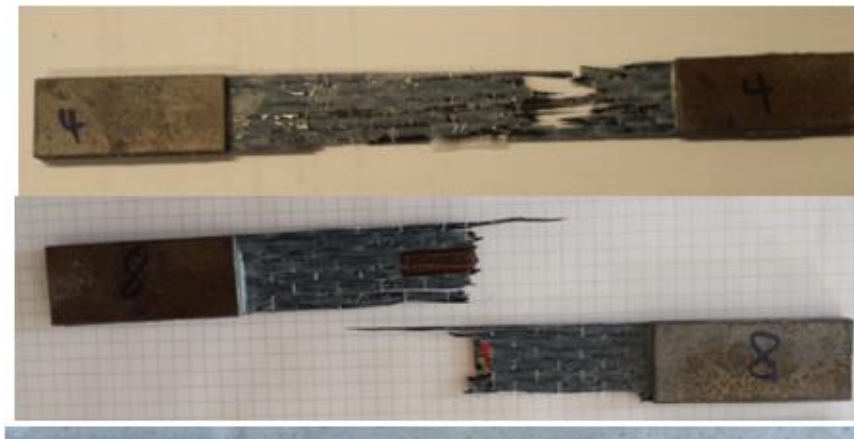

$$
\text { 2xps - } 01
$$
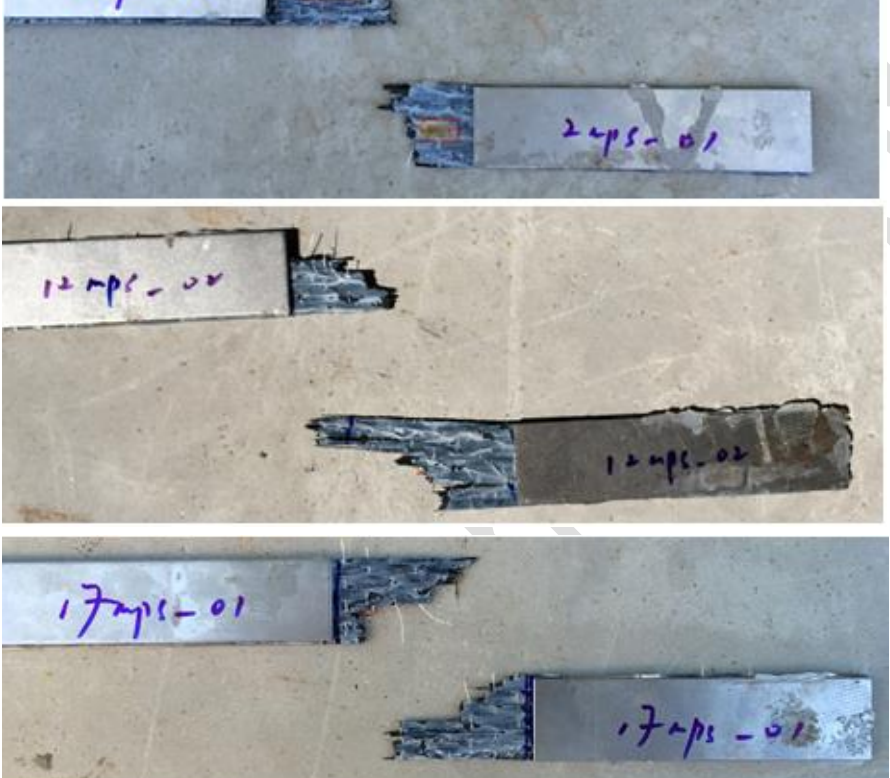

$-7$

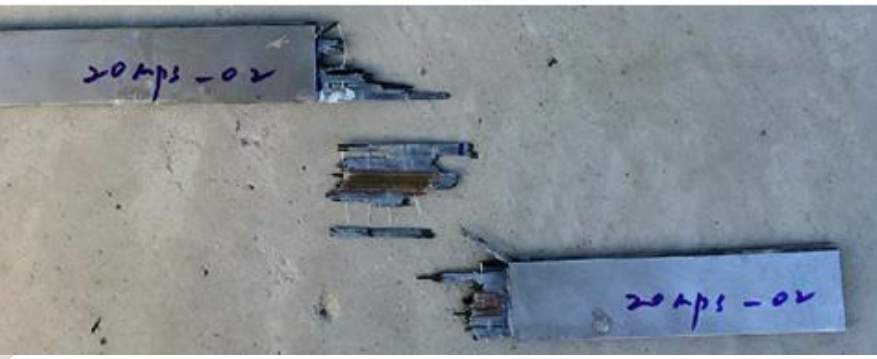

Figure 20 Failure patterns of CFRP specimens

4 


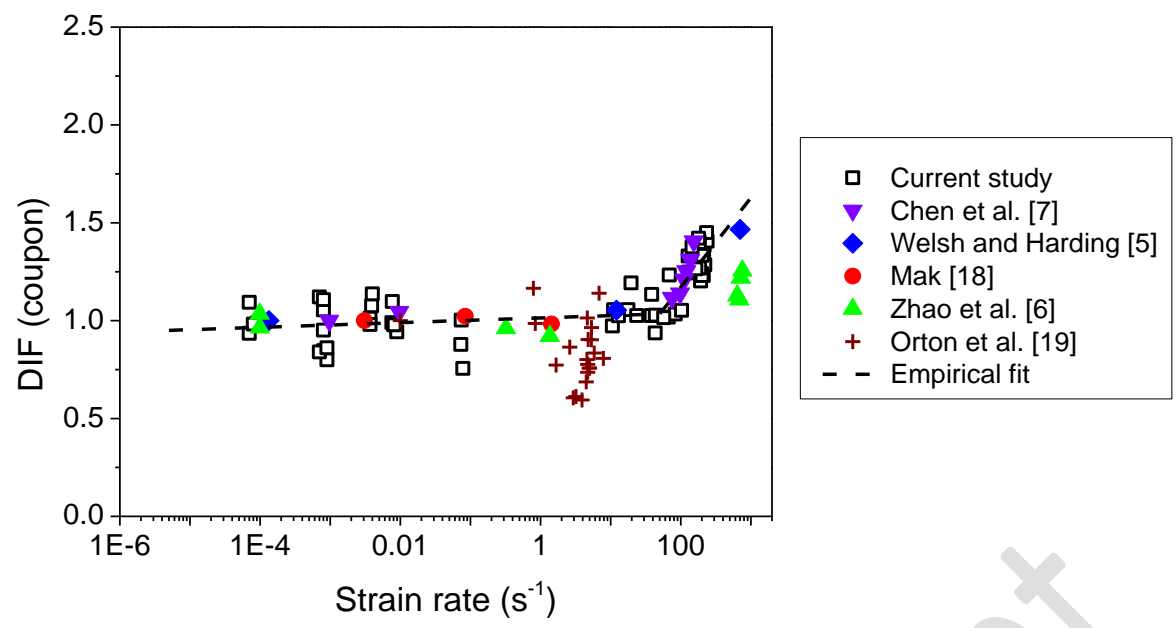

2

Figure 21 DIF of coupon strength versus strain rate

3 


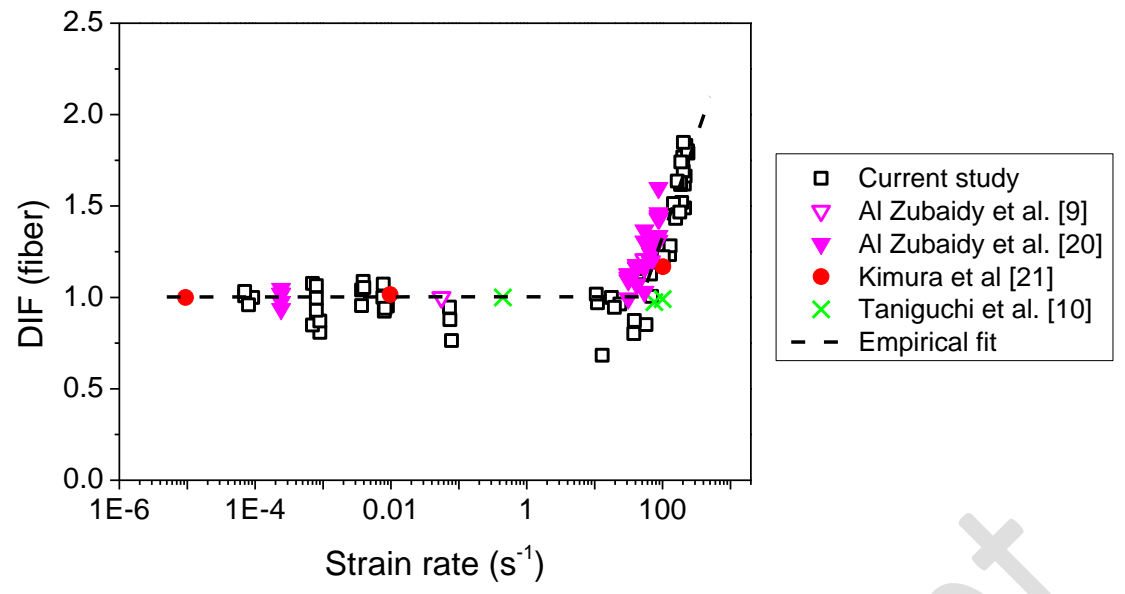

Figure 22 DIF of fiber strength versus strain rate

5 


\begin{tabular}{|c|c|c|c|c|c|c|c|}
\hline $\begin{array}{c}\text { Specimen } \\
\text { No. }\end{array}$ & $\begin{array}{l}\text { Gauge } \\
\text { length } \\
(\mathrm{mm})\end{array}$ & $\begin{array}{l}\text { Width } \\
(\mathrm{mm})\end{array}$ & $\begin{array}{c}\text { Fiber } \\
\text { thickness } \\
(\mathrm{mm})\end{array}$ & $\begin{array}{c}\text { Coupon } \\
\text { thickness } \\
(\mathrm{mm})\end{array}$ & $\begin{array}{l}\text { Extension } \\
\text { rate } \\
(\mathrm{mm} / \mathrm{min})\end{array}$ & $\begin{array}{c}\text { Strain rate } \\
\text { (machine) } \\
\left(\mathrm{s}^{-1}\right)\end{array}$ & $\begin{array}{c}\text { Strain rate } \\
\text { (gauge) } \\
\left(\mathrm{s}^{-1}\right)\end{array}$ \\
\hline 1 & 127 & 24.91 & 0.131 & 0.66 & 1 & $1.31 \mathrm{E}-04$ & 7.00E-05 \\
\hline 2 & 127.5 & 24.88 & 0.131 & 0.54 & 1 & $1.31 \mathrm{E}-04$ & $9.20 \mathrm{E}-05$ \\
\hline 3 & 128 & 24.84 & 0.131 & 0.57 & 1 & 1.30E-04 & 7.00E-05 \\
\hline 4 & 128 & 24.56 & 0.131 & 0.58 & 1 & $1.30 \mathrm{E}-04$ & 8.00E-05 \\
\hline 5 & 128 & 24.61 & 0.131 & 0.66 & 1 & $1.30 \mathrm{E}-04$ & 8.00E-04 \\
\hline 6 & 127 & 24.68 & 0.131 & 0.59 & 10 & $1.31 \mathrm{E}-03$ & $9.00 \mathrm{E}-04$ \\
\hline 7 & 128 & 24.44 & 0.131 & 0.57 & 10 & $1.30 \mathrm{E}-03$ & 7.00E-04 \\
\hline 8 & 128 & 24.45 & 0.131 & 0.64 & 10 & $1.30 \mathrm{E}-03$ & 7.00E-04 \\
\hline 9 & 128 & 24.51 & 0.131 & 0.57 & 10 & $1.30 \mathrm{E}-03$ & 8.00E-04 \\
\hline 10 & 128 & 24.53 & 0.131 & 0.64 & 10 & 1.30E-03 & $9.00 \mathrm{E}-04$ \\
\hline 11 & 129 & 24.36 & 0.131 & 0.58 & 10 & $1.29 \mathrm{E}-03$ & 8.00E-04 \\
\hline 12 & 130 & 24.87 & 0.131 & 0.60 & 10 & $1.28 \mathrm{E}-03$ & 8.00E-04 \\
\hline 13 & 129 & 24.47 & 0.131 & 0.57 & 50 & $6.46 \mathrm{E}-03$ & 3.70E-03 \\
\hline 14 & 129 & 25.06 & 0.131 & 0.66 & 50 & $6.46 \mathrm{E}-03$ & 3.70E-03 \\
\hline 15 & 129 & 24.97 & 0.131 & 0.64 & 50 & $6.46 \mathrm{E}-03$ & $3.90 \mathrm{E}-03$ \\
\hline 16 & 129.5 & 24.83 & 0.131 & 0.57 & 50 & $6.44 \mathrm{E}-03$ & 4.00E-03 \\
\hline 17 & 127 & 24.52 & 0.131 & 0.68 & 100 & $1.31 \mathrm{E}-02$ & 8.90E-03 \\
\hline 18 & 127.5 & 24.49 & 0.131 & 0.66 & 100 & $1.31 \mathrm{E}-02$ & 7.60E-03 \\
\hline 19 & 128 & 24.48 & 0.131 & 0.57 & 100 & $1.30 \mathrm{E}-02$ & 8.00E-03 \\
\hline 20 & 129 & 24.54 & 0.131 & 0.59 & 100 & $1.29 \mathrm{E}-02$ & 7.70E-03 \\
\hline 21 & 129 & 24.72 & 0.131 & 0.57 & 100 & $1.29 E-02$ & 8.20E-03 \\
\hline 22 & 127 & 24.46 & 0.131 & 0.55 & 1000 & $1.31 \mathrm{E}-01$ & 7.40E-02 \\
\hline 23 & 127 & 24.53 & 0.131 & 0.61 & 1000 & $1.31 \mathrm{E}-01$ & $7.80 \mathrm{E}-02$ \\
\hline 24 & 130 & 24.90 & 0.131 & 0.66 & 1000 & $1.28 \mathrm{E}-01$ & 7.30E-02 \\
\hline
\end{tabular}

Table 1 Specimen configurations in the quasi-static and low-speed tests 


\begin{tabular}{|c|c|c|c|c|c|c|c|}
\hline $\begin{array}{c}\text { Specimen } \\
\text { No. }\end{array}$ & $\begin{array}{l}\text { Actuator } \\
\text { speed } \\
(\mathrm{m} / \mathrm{s})\end{array}$ & $\begin{array}{c}\text { Gauge } \\
\text { length } \\
(\mathrm{mm})\end{array}$ & $\begin{array}{l}\text { Width } \\
(\mathrm{mm})\end{array}$ & $\begin{array}{c}\text { Fiber } \\
\text { thickness } \\
(\mathrm{mm})\end{array}$ & $\begin{array}{l}\text { Coupon } \\
\text { thickness } \\
(\mathrm{mm})\end{array}$ & $\begin{array}{l}\text { Peak load } \\
\quad(k N)\end{array}$ & $\begin{array}{l}\text { Strain rate } \\
\qquad\left(\mathrm{s}^{-1}\right)\end{array}$ \\
\hline 1_03 & 1 & 50 & 25.3 & 0.131 & 0.58 & 11.38 & 10.59 \\
\hline 1_02 & 1 & 50 & 25.2 & 0.131 & 0.52 & 9.85 & 11.04 \\
\hline 1_01 & 1 & 50 & 23.4 & 0.131 & 0.46 & 6.45 & 12.94 \\
\hline 2_03 & 2 & 50 & 25.0 & 0.131 & 0.53 & 10.07 & 17.66 \\
\hline 2_01 & 2 & 50 & 24.5 & 0.131 & 0.49 & 9.34 & 19.57 \\
\hline 2_02 & 2 & 50 & 24.6 & 0.131 & 0.58 & 11.35 & 23.58 \\
\hline 4_03 & 4 & 50 & 23.2 & 0.131 & 0.50 & 7.50 & 37.83 \\
\hline 4_04 & 4 & 50 & 23.8 & 0.131 & 0.49 & 8.38 & 38.54 \\
\hline 4_02 & 4 & 50 & 25.8 & 0.131 & 0.59 & 11.80 & 43.30 \\
\hline 4_01 & 4 & 50 & 25.7 & 0.131 & 0.57 & 11.99 & 43.50 \\
\hline 5_03 & 5 & 50 & 23.9 & 0.131 & 0.51 & 8.20 & 57.18 \\
\hline 5_02 & 5 & 50 & 25.3 & 0.131 & 0.57 & 11.50 & 66.65 \\
\hline 5_01 & 5 & 50 & 24.2 & 0.131 & 0.50 & 9.81 & 68.76 \\
\hline 7_03 & 7 & 50 & 25.2 & 0.131 & 0.59 & 12.41 & 83.34 \\
\hline 7_01 & 7 & 50 & 25.6 & 0.131 & 0.58 & 12.61 & 102.97 \\
\hline 10_01 & 10 & 50 & 24.5 & 0.131 & 0.53 & 12.18 & 127.52 \\
\hline 10_02 & 10 & 50 & 24.3 & 0.131 & 0.56 & 12.56 & 129.53 \\
\hline $12 \_01$ & 12 & 50 & 25.1 & 0.131 & 0.57 & 15.31 & 145.13 \\
\hline $12 \_02$ & 12 & 50 & 25.4 & 0.131 & 0.58 & 14.67 & 156.41 \\
\hline 15_01 & 15 & 50 & 25.8 & 0.131 & 0.61 & 17.02 & 164.56 \\
\hline 15_02 & 15 & 50 & 25.3 & 0.131 & 0.55 & 14.95 & 179.57 \\
\hline 15_03 & 15 & 50 & 25.5 & 0.131 & 0.58 & 16.62 & 184.51 \\
\hline 16_01 & 16 & 50 & 25.6 & 0.131 & 0.61 & 16.80 & 185.13 \\
\hline 16_02 & 16 & 50 & 25.6 & 0.131 & 0.63 & 17.96 & 186.16 \\
\hline 16_03 & 16 & 50 & 25.2 & 0.131 & 0.61 & 15.44 & 191.75 \\
\hline 17_01 & 17 & 50 & 25.8 & 0.131 & 0.64 & 18.38 & 199.01 \\
\hline 17_02 & 17 & 50 & 25.7 & 0.131 & 0.63 & 17.52 & 202.10 \\
\hline 17_03 & 17 & 50 & 25.9 & 0.131 & 0.63 & 19.29 & 202.76 \\
\hline 18_01 & 18 & 50 & 25.4 & 0.131 & 0.62 & 16.58 & 210.14 \\
\hline 18_02 & 18 & 50 & 25.2 & 0.131 & 0.57 & 15.13 & 211.59 \\
\hline 18_03 & 18 & 50 & 25.6 & 0.131 & 0.59 & 17.16 & 215.98 \\
\hline 20_01 & 20 & 50 & 25.8 & 0.131 & 0.64 & 19.04 & 220.39 \\
\hline 20_02 & 20 & 50 & 25.6 & 0.131 & 0.60 & 18.59 & 233.52 \\
\hline 20_03 & 20 & 50 & 25.8 & 0.131 & 0.61 & 18.61 & 237.32 \\
\hline
\end{tabular}




\begin{tabular}{|c|c|c|c|c|c|c|c|c|}
\hline No. & $\begin{array}{l}\text { Strain rate } \\
\qquad\left(s^{-1}\right)\end{array}$ & $\begin{array}{c}\text { Failure } \\
\text { strain }\end{array}$ & $\begin{array}{c}\text { Fiber } \\
\text { strength } \\
(\mathrm{MPa})\end{array}$ & $\begin{array}{c}\text { Coupon } \\
\text { strength } \\
(\mathrm{MPa})\end{array}$ & $\begin{array}{c}\text { Fiber } \\
\text { modulus } \\
(\mathrm{GPa})\end{array}$ & $\begin{array}{c}\text { Coupon } \\
\text { stiffness } \\
(\mathrm{GPa})\end{array}$ & $\begin{array}{c}\text { Fiber } \\
\text { DIF }\end{array}$ & $\begin{array}{c}\text { Coupon } \\
\text { DIF }\end{array}$ \\
\hline 1 & 7.00E-05 & 0.0108 & 3101.91 & 634.92 & 228.60 & 46.80 & 1.01 & 0.93 \\
\hline 2 & $9.20 \mathrm{E}-05$ & 0.0098 & 3075.91 & 671.57 & 221.40 & 48.60 & 1.00 & 0.99 \\
\hline 3 & $7.00 \mathrm{E}-05$ & 0.0113 & 3176.35 & 743.04 & 198.00 & 46.80 & 1.03 & 1.09 \\
\hline 4 & 8.00E-05 & 0.0109 & 2953.22 & 667.02 & 225.00 & 50.40 & 0.96 & 0.98 \\
\hline 5 & 8.00E-04 & 0.0098 & 2634.75 & 575.25 & 203.40 & 45.00 & 0.86 & 0.85 \\
\hline 6 & $9.00 \mathrm{E}-04$ & 0.0098 & 2488.62 & 543.35 & 216.00 & 46.80 & 0.81 & 0.80 \\
\hline 7 & $7.00 \mathrm{E}-04$ & 0.0100 & 3313.34 & 761.49 & 247.95 & 54.90 & 1.08 & 1.12 \\
\hline 8 & 7.00E-04 & 0.0098 & 2612.53 & 570.40 & 216.00 & 46.80 & 0.85 & 0.84 \\
\hline 9 & 8.00E-04 & 0.0106 & 3062.09 & 716.31 & 224.10 & 52.20 & 1.00 & 1.05 \\
\hline 10 & $9.00 \mathrm{E}-04$ & 0.0098 & 2680.32 & 585.20 & 202.50 & 44.10 & 0.87 & 0.86 \\
\hline 11 & 8.00E-04 & 0.0109 & 2860.35 & 646.05 & 229.50 & 52.20 & 0.93 & 0.95 \\
\hline 12 & 8.00E-04 & 0.0111 & 3273.24 & 752.27 & 229.50 & 53.10 & 1.06 & 1.11 \\
\hline 13 & 3.70E-03 & 0.0105 & 2939.32 & 687.59 & 222.30 & 52.20 & 0.96 & 1.01 \\
\hline 14 & 3.70E-03 & 0.0107 & 3201.79 & 665.77 & 243.00 & 50.40 & 1.04 & 0.98 \\
\hline 15 & $3.90 \mathrm{E}-03$ & 0.0112 & 3347.20 & 730.80 & 230.40 & 50.40 & 1.09 & 1.08 \\
\hline 16 & 4.00E-03 & 0.0111 & 3241.99 & 772.18 & 227.70 & 53.10 & 1.05 & 1.14 \\
\hline 17 & 8.90E-03 & 0.0098 & 2931.93 & 640.14 & 214.20 & 45.90 & 0.95 & 0.94 \\
\hline 18 & 7.60E-03 & 0.0109 & 3078.49 & 672.14 & 214.20 & 46.80 & 1.00 & 0.99 \\
\hline 19 & 8.00E-03 & 0.0097 & 2843.03 & 665.07 & 225.00 & 52.20 & 0.92 & 0.98 \\
\hline 20 & 7.70E-03 & 0.0108 & 3301.70 & 745.73 & 198.00 & 45.00 & 1.07 & 1.10 \\
\hline 21 & 8.20E-03 & 0.0107 & 2892.76 & 664.83 & 180.00 & 43.20 & 0.94 & 0.98 \\
\hline 22 & $7.40 \mathrm{E}-02$ & 0.0100 & 2702.82 & 680.90 & 189.00 & 46.80 & 0.88 & 1.00 \\
\hline 23 & $7.80 \mathrm{E}-02$ & 0.0102 & 2351.45 & 513.40 & 171.00 & 38.70 & 0.76 & 0.76 \\
\hline 24 & 7.30E-02 & 0.0121 & 2914.35 & 596.53 & 158.95 & 36.00 & 0.95 & 0.88 \\
\hline
\end{tabular}




\begin{tabular}{|c|c|c|c|c|c|c|c|c|}
\hline $\begin{array}{c}\text { Specimen } \\
\text { No. }\end{array}$ & $\begin{array}{c}\text { Strain } \\
\text { rate } \\
\left(\mathrm{s}^{-1}\right) \\
\end{array}$ & $\begin{array}{l}\text { Failure } \\
\text { strain }\end{array}$ & $\begin{array}{c}\text { Fiber } \\
\text { strength } \\
(\mathrm{MPa})\end{array}$ & $\begin{array}{c}\text { Fiber } \\
\text { modulus } \\
(\mathrm{GPa})\end{array}$ & $\begin{array}{c}\text { Coupon } \\
\text { strength } \\
(\mathrm{MPa})\end{array}$ & $\begin{array}{c}\text { Coupon } \\
\text { stiffness } \\
(\mathrm{GPa})\end{array}$ & $\begin{array}{l}\text { Fiber } \\
\text { DIF }\end{array}$ & $\begin{array}{c}\text { Coupon } \\
\text { DIF }\end{array}$ \\
\hline 1_03 & 10.59 & 0.0114 & 3131.94 & 274.25 & 660.73 & 57.86 & 1.02 & 0.97 \\
\hline 1_02 & 11.04 & 0.0123 & 2985.20 & 243.61 & 717.38 & 58.54 & 0.97 & 1.06 \\
\hline 1_01 & 12.94 & 0.0099 & 2103.80 & 211.65 & 695.75 & 69.99 & 0.68 & 1.02 \\
\hline 2_03 & 17.66 & 0.0128 & 3076.17 & 240.47 & 717.30 & 56.07 & 1.00 & 1.06 \\
\hline 2_01 & 19.57 & 0.0110 & 2909.61 & 264.69 & 809.95 & 73.68 & 0.95 & 1.19 \\
\hline 2_02 & 23.58 & 0.0113 & 2965.16 & 261.71 & 696.85 & 61.50 & 0.96 & 1.03 \\
\hline 4_03 & 37.83 & 0.0138 & 2468.96 & 178.39 & 697.05 & 50.37 & 0.80 & 1.03 \\
\hline 4_04 & 38.54 & 0.0110 & 2688.62 & 244.88 & 770.44 & 70.17 & 0.87 & 1.13 \\
\hline 4_02 & 43.30 & 0.0120 & 3491.13 & 290.59 & 636.54 & 52.98 & 1.13 & 0.94 \\
\hline 4_01 & 43.50 & 0.0113 & 3560.19 & 315.78 & 698.19 & 61.93 & 1.16 & 1.03 \\
\hline 5_03 & 57.18 & 0.0101 & 2617.71 & 258.97 & 689.55 & 68.22 & 0.85 & 1.02 \\
\hline 5_02 & 66.65 & 0.0130 & 3470.62 & 267.43 & 691.38 & 53.27 & 1.13 & 1.02 \\
\hline 5_01 & 68.76 & 0.0108 & 3094.69 & 287.22 & 837.61 & 77.74 & 1.01 & 1.23 \\
\hline 7_03 & 83.34 & 0.0120 & 3760.62 & 314.45 & 702.00 & 58.70 & 1.22 & 1.03 \\
\hline 7_01 & 102.97 & 0.0116 & 3760.83 & 325.03 & 715.10 & 61.80 & 1.22 & 1.05 \\
\hline 10_01 & 127.52 & 0.0146 & 3796.35 & 259.28 & 903.29 & 61.69 & 1.23 & 1.33 \\
\hline 10_02 & 129.53 & 0.0122 & 3944.77 & 322.51 & 847.66 & 69.30 & 1.28 & 1.25 \\
\hline 12_01 & 145.13 & 0.0119 & 4657.69 & 391.40 & 935.25 & 78.59 & 1.51 & 1.38 \\
\hline $12 \_02$ & 156.41 & 0.0133 & 4407.87 & 331.47 & 844.73 & 63.52 & 1.43 & 1.24 \\
\hline 15_01 & 164.56 & 0.0119 & 5035.16 & 422.34 & 858.85 & 72.04 & 1.64 & 1.26 \\
\hline 15_02 & 179.57 & 0.0113 & 4511.48 & 399.50 & 965.28 & 85.48 & 1.47 & 1.42 \\
\hline 15_03 & 184.51 & 0.0130 & 4976.00 & 382.89 & 949.87 & 73.09 & 1.62 & 1.40 \\
\hline 16_01 & 185.13 & 0.0124 & 5008.97 & 405.04 & 861.05 & 69.63 & 1.63 & 1.27 \\
\hline 16_02 & 186.16 & 0.0123 & 5356.23 & 436.39 & 863.22 & 70.33 & 1.74 & 1.27 \\
\hline 16_03 & 191.75 & 0.0132 & 4675.81 & 353.78 & 816.54 & 61.78 & 1.52 & 1.20 \\
\hline 17_01 & 199.01 & 0.0141 & 5438.23 & 386.52 & 842.67 & 59.89 & 1.77 & 1.24 \\
\hline 17_02 & 202.10 & 0.0129 & 5204.86 & 402.22 & 835.56 & 64.57 & 1.69 & 1.23 \\
\hline 17_03 & 202.76 & 0.0137 & 5685.99 & 416.18 & 905.75 & 66.29 & 1.85 & 1.33 \\
\hline 18_01 & 210.14 & 0.0161 & 4982.38 & 309.20 & 835.60 & 51.86 & 1.62 & 1.23 \\
\hline 18_02 & 211.59 & 0.0151 & 4582.63 & 303.49 & 916.53 & 60.70 & 1.49 & 1.35 \\
\hline 18_03 & 215.98 & 0.0155 & 5117.33 & 329.86 & 940.33 & 60.61 & 1.66 & 1.38 \\
\hline 20_01 & 220.39 & 0.0143 & 5633.26 & 394.16 & 872.89 & 61.08 & 1.83 & 1.29 \\
\hline 20_02 & 233.52 & 0.0138 & 5542.96 & 401.40 & 984.87 & 71.32 & 1.80 & 1.45 \\
\hline 20_03 & 237.32 & 0.0145 & 5506.49 & 380.40 & 954.83 & 65.96 & 1.79 & 1.41 \\
\hline
\end{tabular}

1

Table 4 Summary of testing results in the high-speed tests 